January 1989

\title{
EPIDEMIOLOGY AND CONTROL OF
}

INFECTIOUS DISEASES OF SALMONIDS

IN THE COLUMBIA RIVER BASIN

Annual Report 1987

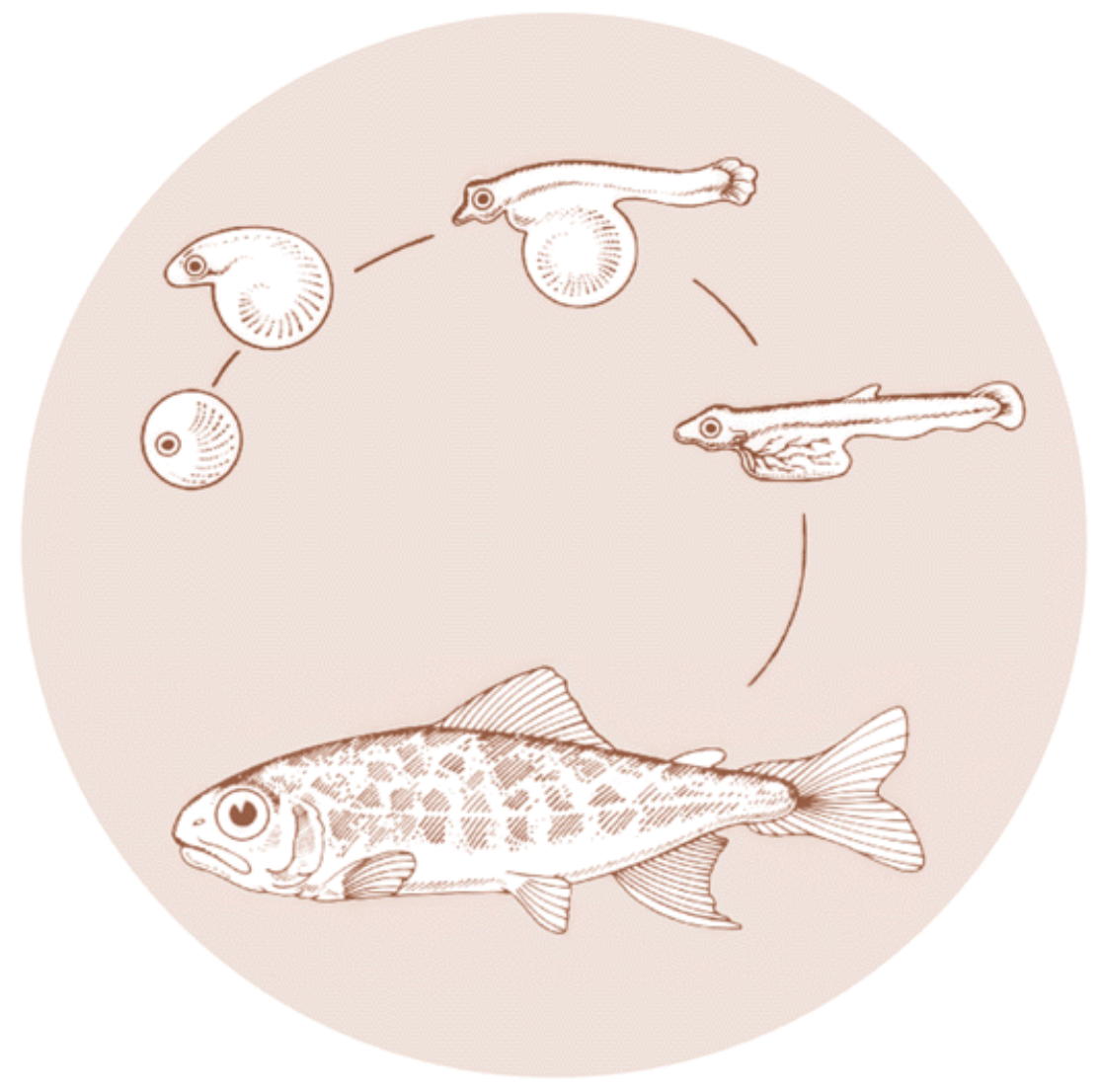

DOE/BP-11987-3 
This report was funded by the Bonneville Power Administration (BPA), U.S. Department of Energy, as part of BPA's program to protect, mitigate, and enhance fish and wildlife affected by the development and operation of hydroelectric facilities on the Columbia River and its tributaries. The views of this report are the author's and do not necessarily represent the views of BPA.

This document should be cited as follows:

Fryer, J. L., Department of Microbiology, Epidemiology and Control of Infectious Diseases of Salmonids in the

Columbia River Basin, Annual Report 1987 to Bonneville Power Administration, Portland, OR, Contract 83-AI-11987,

Project 83-312, 130 electronic pages (BPA Report DOE/BP-11987-3)

This report and other BPA Fish and Wildlife Publications are available on the Internet at:

\section{http://www.efw.bpa.gov/cgi-bin/efw/FW/publications.cgi}

For other information on electronic documents or other printed media, contact or write to:

Bonneville Power Administration

Environment, Fish and Wildlife Division

P.O. Box 3621

905 N.E. 11th Avenue

Portland, OR 97208-3621

Please include title, author, and DOE/BP number in the request. 


\title{
EPIDEMIOLOGY AND CONTROL OF INFECTIOUS DISEASES OF SALMONIDS IN THE COLUMBIA RIVER BASIN
}

\author{
Annual Report 1987
}

\author{
Prepared by: \\ J. L. Fryer \\ Department of Microbiology
}

Prepared for:

U.S. Department of Energy

Bonneville Power Administration Environment, Fish and Wildlife

PO Box 3621

Portland, Oregon 97208

Project No. 83-312

Contract No. DE-AI79-83BP11987

January 1989 
Acknowledgements

Abstract

Chapter I. Development, Characterization, and Use of

Monoclonal and Polyclonal Antibodies against the Myxosporean, Ceratomyxa Shasta.

$\begin{array}{lr}\text { Abstract } & 2 \\ \text { Introduction } & 3 \\ \text { Materials and Methods } & 5 \\ \text { Results } & 11 \\ \text { Discussion } & 23 \\ \text { Acknowledgements } & 26 \\ \text { Literature Cited } & 27\end{array}$

Chapter II. Characterization of the Host Response to the Myxosporean parasite, Ceratomyxa Shasta, by Histology, Scanning Electron Microscopy, and Immunological Techniques. 29

$\begin{array}{ll}\text { Abstract } & 30 \\ \text { Introduction } & 31 \\ \text { Materials and Methods } & 35 \\ \text { Results } & 39 \\ \text { Discussion } & 55 \\ \text { Acknowledgements } & 62 \\ \text { Literature Cited } & 63\end{array}$

Chapter III. Characterization of a Monoclonal Antibody against Ceratomyxa Shasta Using Immunocytochemistry.

Abstract

Introduction

67

Materials and Methods

68

Results and Discussion

69

Acknowledgements

70

Literature Cited 
TABLE OF CONTENTS (continued)

Page

Chapter IV. Artificial Transmission of Ceratomyxa Shasta Via Potential Intermediates 79

Abstract

Introduction

Materials and Methods

Results and Discussion

89

Acknowledgements

95

Literature Cited

96

Chapter V. In Vitro Inhibition of Renibacterium Salmoninarum

by Experimental Antibiotics. 97

Abstract 98

Introduction 99

Materials and Methods 100

Results 104

Discussion 116

Acknowledgements $\quad 120$

Literature Cited 121

$\begin{array}{lr}\text { Summary of Expenditures } & 122\end{array}$ 


\section{ACKNOWLEDGEMENTS}

Support for this research came from the region's electrical rate payers through the Bonneville Power Administration.

The cooperation of the Environmental Protection Agency Corvallis Environmental Research Laboratory is recognized for their providing some of the fish holding facilities at the Western Fish Toxicology Laboratory; The Oregon Department of Fish and Wildlife provided experimental fish. Pfizer; Merck, Sharp and Dohme Research Laboratories, Abbot Laboratories; and Lily Research Laboratories have supplied antimicrobial agents. 


\begin{abstract}
The Department of Microbiology at Oregon State University with funding from the Bonneville Power Administration has been conducting a study concerning the epidemiology and control of three fish pathogens which cause major disease problems in salmonids of the Columbia River basin. The pathogens studied include Cera to $\mathrm{m}$ yxa Shasta, the myxosporean parasite which causes ceratomyxosis; Renibacterium salmoninarum, the bacterium which is the etiological agent of bacterial kidney disease; and the rhabdovirus which causes infectious hematopoietic necrosis (IHN). During this project, the host and geographic range of C. Shasta have been more precisely determined and the known geographic range has been significantly expanded. The effects of the parasite on fish migrating through the Columbia River and on their introduction into salt water have been examined. Similar studies have been conducted with $\mathbf{R}$. salmoninarum and it has been shown that bacterial kidney disease occurs at all life stages of salmonids and is responsible for mortality in both fresh and salt water. It has also been demonstrated that different isolates of $\mathbf{R}$. salmoninarum have different antigenic composition. Results of demonstration projects designed to control IHN by using UV treated water for early rearing of salmonid fry were equivocal.

The scope of the project was considerably narrowed and focused during the past two years The project has concentrated on a study concerning the biology of $\mathbf{C}$. Shasta and the identification of potential chemotherapeutants for control of bacterial kidney disease.
\end{abstract}


The emphasis of work on C. Shasta has been its pathogenesis. This aspect of the parasite has been investigated using histopathologic and immunologic methodology. Mode of transmission, the nature of the infectious stage, and potential intermediate hosts of the parasite have also been areas of active research.

Classes of chemotherapeutants with the highest potential for efficacy against $\mathbf{R}$. salmoninarum have been identified through literature searches and consultation with pharmacologists. Experimental drugs have been requested and received from several pharmaceutical manufacturers. The in vitro sensitivity of $\mathbf{R}$. salmoninarum and other selected fish pathogens to more than 100 antimicrobial compounds has been tested.

The project is related to measure $704(\mathrm{~h})(2)(\mathrm{d})$ of the Columbia River Basin Fish and Wildlife Program. The results will contribute to fish health which will directly contribute to the protection of fish. 
CHAPTER I

DEVELOPMENT, CHARACTERIZATION, AND USE OF MONOCLONAL AND POLYCLONAL ANTIBODIES AGAINST THE MYXOSPOREAN, CERATOMYXA SHASTA

J.L. Bartholomew, J.S. Rohovec, and J.L. Fryer

\author{
Department of Microbiology \\ Oregon State University \\ Corvallis, Oregon 97331, USA
}




\begin{abstract}
Both monoclonal- and polyclonal antisera were produced against Ceratomyxa Shasta. Ascites containing trophozoites of the parasite was collected from infected fish and used as antigen for immunization of mice. The resulting monoclonal antibodies reacted specifically with trophozoite and sporoblast stages but did not react with C. Shasta spores by either indirect fluorescent antibody techniques or in Western blots. This indicates that C. Shasta contains unique antigens and that some of these antigens are specific to certain life stages of the parasite. Polyclonal antiserum was produced in a rabbit by injecting a spore protein electroeluted from an SDS-polyacrylamide gel. This antiserum reacted with both trophozoites and spores by indirect fluorescent antibody techniques and in Western blots. All antisera were tested for cross-reactivity to trout white blood cells, a contaminant of the ascites, and to other myxosporeans. Two monoclonal antibodies reacted with white blood cells and myxosporeans of the genera Sp haerospora and
\end{abstract} Myxobilatus. One hybridoma produced antibodies of high specificity for C. Shasta prespore stages. This is the first report of a monoclonal antibody produced against a myxosporean parasite. 


\section{INTRODUCTION}

The myxosporean parasite, Ceratomyxa Shasta (Noble, 1950) causes an intestinal disease in susceptible salmonid fish in the Pacific Northwest region of the United States and Canada. This parasite has been responsible for epizootics in both wild and hatchery populations of salmonids. At present there is no effective means of control other than avoidance of the infectious stage of this organism and stocking of resistant strains of salmonids in endemic areas. Spores of C. Shasta are easily detected in moribund fish; however, the infectious process is temperature dependent, with mortality occurring about 56 days post-exposure among fish held at $12^{\circ} \mathrm{C}$, (Udey et al., 1975). Development of mature spores occurs just prior to death of the host, but before spore formation, trophozoite stages of the parasite are abundant in the intestinal tract. While these stages may be identified using histological techniques, they often go undetected by microscopic examination of intestinal tract scrapings, the standard diagnostic procedure. The similarity of the multinuclear trophozoites to the same life stages of other myxosporeans also complicates diagnosis.

The life cycle of C. Shasta, like that of most myxosporeans, remains unknown. The morphology of the infective stage and the initial site of infection in the host have not been determined, Attempts to transmit the disease by feeding infected tissues, cohabitation of infected and susceptible fish, and exposing susceptible fish to a mixture of mud and infected tissues have 
failed (Johnson et al., 1979). The inability to transmit the disease between susceptible fish has led to speculation that an intermediate host may be necessary. The life cycle of another myxosporean parasite, Myxobolus cerebralis, was shown by Wolf and Markiw (1984) to require Tubifex tubifex as an intermediate host. They were also able to demonstrate, that within the oligochaete, the myxosporean spore transforms into a form previously identified as a triactinomyxon. This alternation of life stages and intermediate host involvement has not yet been demonstrated for C. Shasta. The usefulness of serological techniques for identifying different life stages has been shown for several human parasites. Results of those' studies indicate that the presence of stage-specific antigens is common to parasites such as Plasmodium vivax and $\mathbf{P}$. ovale (Andrysiak et al., 1986), and Trypanosoma cruzi (Wrightsman et al., 1986). This paper presents immunological evidence of stagespecific C. Shasta antigens which accompany the morphological change from trophozoite to spore and is the first report of monoclonal antibodies produced against a myxosporean parasite. The use of specific antibodies for diagnostic purposes is also described. 


\section{MATERIALS AND METHODS}

\section{Antigen}

Ascites containing prespore (trophozoite and disporoblast) stages of C . shasta was collected from naturally infected rainbow trout. Cells were pelleted by centrifugation (1500 g) and washed twice in $0.1 \mathrm{M}$ phosphate-buffered saline $\mathrm{pH} 7.6$ (PBS). This antigen was used both for injection of mice for hybridoma production and for all screening procedures.

Spore stages of C .shasta were collected from the intestinal tract of infected rainbow trout. After homogenization of the tissue and low-speed centrifugation (1500 g) to remove fish tissue, the spores were layered onto a $12-75 \%(\mathrm{v} / \mathrm{v})$ gradient of modified colloidal silica (Percoll, stock density $1.13 \mathrm{~g} / \mathrm{ml}$ ) (Sigma Chemical Co., St Louis, MO). Gradients were centrifuged at $1500 \mathrm{~g}$ for $35 \mathrm{~min}$ in a swinging bucket rotor. Spores were layered on top of the $75 \%$ Percoll. This band was removed and the spores washed twice in PBS. Spores were used for screening hybridoma supernatants and for polyclonal antiserum production.

To obtain white blood cells, rainbow trout were bled from the caudal vein. Blood was stored in heparin $(15 \mathrm{IU} / \mathrm{ml})$ for one hour, cells were pelleted by centrifugation at $2500 \mathrm{~g}$, washed twice and resuspended in PBS. The buffy coat was collected after overnight refrigeration. 


\section{Hybridoma Production}

Monoclona antibodies (Mabs) were produced by the method of Campbell (1984) . Briefly, for the production of antibodies specific to C. shasta freshly collected prespore stages (106 total/mouse) suspended in PBS were injected intraperitoneally into Balb/c mice. Two booster injections were given at one month intervals . Antibody production was evaluated by indirect fluorescent antibody technique (BFAT) on cells from th eascites of infected rainbow trout .Four days after the second booster, the mice were primed with an injection of 106 parasites. Four days later the spleen cells were removed and fused with a non-secreting tumor line ,SP2/0, at a ratio o $5: 1$, using polyethylene glycol $(80 \%$ PEG 1500, 20\% PEG 4000). The cells were distributed in 96 well microtiter plates (Costar Çambridge, Mass) in selective medium (RPM1 with $10 \%$ (v/v) fetal calf serum plus hypoxanthine, aminopterin , and thymidine), and incubated at $370 \mathrm{C}$ in $5 \% \mathrm{C} 02$. After 14 days, supernatants were screened for antibodies specific for C. Shasta. A dot-immunobinding assay (Hawkes et al., 1982) using prespore stages fro nascites as antigen was the primary test for reactivity. Supernatants eliciting a positive reaction were screened again $b$ yIFAT using cells from th eascites of infected fish and fish blood cells from uninfected fish as antigens Those hybridomas producing antibodies positive only for cells from infected rainbow trout were cloned by limiting dilution. The supernatants from wells with single clones were tested for antibody as described; positive hybridomas were again cloned by limiting 
dilution and reassayed afte 10-14 days. Selected hybridomas were expanded into $75 \mathrm{~cm} 2$ flasks and maintained i RPMI (Sigma Chemical Co.) plus 10\% (v/v) fetal bovine serum (Hyclone Laboratories, Logan, Utah) .The immunoglobulin class and subclass produced by each hybridoma was determined by an enzyme-linked immunoassay (Mous monoclona subisotyping kit HyClone Laboratories).

Western blot analysis was performed using antibodies from the expanded clones. Following electrophoretic separation of $\mathrm{C}$. shasta spores, prespore stages, and fis WBCs, on a $12 \%$ sodium dodecyl sulfate-polyacrylamide gel (SDS-PAGE), the antigens were transferred to nitrocellulose by electroblotting in a Trans-blot cell (Bio-Rad Laboratories, Richmond, CA). The nitrocellulose was then probed with hybridoma supernatants and peroxidase-labeled goat anti-mouse serum (Hyclone Laboratories). Antibodies whic crobsreacted with fish WBC antigens were further characterized by Western blot analysis, using immunized fish sera as a source of antigen, and by enzyme-linked immunoassay (ELISA). In the ELISA, the cross-reacting Mabs were used as a second antibody. Plates were coated with trinitrophenyl-bovine serum albumin (TNP-BSA) and incubated with trout anti-TNP antiserum as primary antibody. In both Western blot and ELISA, a noncross-reacting Mab was used as a negative control and a Mab produced against fish immunoglobulin (cell line 1-14, a gift of Dr. G. Warr, Dept. of Biochemistry, Univ of South Carolina) served as a positive control. Antibodies specific for carbohydrate epitopes were detected by 
periodate oxidation of the antigens on nitrocellulose (Woodward et al., 1985). Briefly, C. shasta prespore stages and fish sera were separated by electrophoresis on a polyacrylamide gel and then transferred onto nitrocellulose After exposing to periodate concentrations from 5-2 onM, blots were incubated with the monoclonal antibodies and probed as described.

Antibodies were also screened for cross-reactivity with other myxosporeans b yIFAT on histological sections from fish infected with the following parasites H:enneguya exilis, Sphaerospora sp., PKX, Chloromyxum majori, Myxobilatus sp., an d Myxobolus cerebralis, and also on purified spores o Henneguya salmincola and Myxobolus insidiosus.

\section{Polyclonal Antiserum}

To obtain the antigen used for the production of polyclonal antisera, 1 x 108 purified spores were diluted :11 with sample buffer (Schleif and Wensink, 1981) and the proteins were separated by SDS-PAGE. The gel was stained with Coomassie blue ( $0.1 \%$ in $40 \%$ methanol and $10 \%$ acetic acid) and the polypeptide profile examined for bands specific to the spore stage. A preparative SDS-PAGE was used to purify a single protein band. After electrophoresis of the spores, a narrow vertical strip of the gel was excised and stained in order to identify the protein bands. The portion of the gel corresponding to the band of interest was excised and the protein electroeluted (Elutrap, Schleicher and Schuell, Keene, NH). A sample of the eluent was diluted :11 in 
sample buffer and run on a gel to assess the purity of the antigen. Antigen was mixed 1:1 with Freund's complete adjuvant and injected into New Zealand white rabbits; $0.5 \mathrm{ml}$ in each footpad and $0.5 \mathrm{ml}$ subcutaneously between the scapula. After four weeks, a booster was administered by injection of the antigen mixed :1 in Freund's incomplete adjuvant. Two weeks later the rabbit was bled and the antiserum tested for specificity $b$ IFyT and Western blot analysis.

\section{IFAT}

Monoclonal or polyclonal antibodies were incubated for 15 minutes at room temperature with cells fixed in acetone-xylene (1: 1). Specific antibodies were detected using biotinylated horse anti-mous eIgG or anti-rabbit Ig and fluorescein isothiocyanate conjugate davidin D (Vector Laboratories, Burlingame, CA) Methyl green dye (1\% in distilled water) was used as a counterstain. Cells were examined using a Zeiss standard microscope with an I Fl Epifluorescenc e condenser.

\section{Histology}

For serological diagnosis of infections in tissue sections, viscera of fish exposed to the infectious stage o C.f shasta were fixed in either Bouin's or $10 \%(\mathrm{v} / \mathrm{v})$ neutral buffered formalin, processed routinely for histology to $6 \mu \mathrm{m}$ and mounted on gelatin coated slides. Sections to be examined b JIFAT were stained as described. Sections for examination by bright light microscopy 
were incubated with specific antibody, then biotinylate antid mous e IgG, and finally with a nvidin DH - biotinylated alkaline phosphatase H complex (Vectastain ABC-AP kit,; Vector Laboratories). The enzymatic activity was localized with an insoluble substrate (Alkaline Phosphate Substrate Kit II; Vector Laboratories). 


\section{RESULTS}

\section{Monoclonal Antibodies}

One fusion resulted in four hybridomas which produced antibodies that reacted positively by dot immunobinding an IFAT to fixed, whole trophozoites fro ascites Isotypes of the immunoglobulins produced by each hybridoma were determined; one Mab was a nIgM and three wer eIgGs, one each IgGl, IgG2a, and IgG3. Hybridoma supernatants were also tested for their reactivity $\mathrm{t} \propto \mathrm{C}$. shasta spores and to fis hWBCs by IFAT (Table 1.1). The Mabs did not react with spores. The pattern of fluorescence of the parasite was similar after reacting with antibodies from each hybridoma.

In Western blot analysis all Mabs recognized antigens from prespore stages o $\mathbf{f C}$. shasta and there were none that reacted with spore antigens. Two Mabs reacted with fish WBC antigens, recognizing a protein with a molecular weight (MW) of approximately 80 kilodaltons (kdal) in both buffy coat preparations and in fish sera (Fig. 1.1) . These Mabs also reacted specifically with fish immunoglobulins in an ELISA. To determine if thes crossreacting antibodies reacted with a protein or carbohydrate epitope, Western transfers of antigens in prespore stages and in fish sera were exposed to varying concentrations of periodate Complete loss of binding of Mabs 1 and 3 occurred at a concentration of 1 mNo periodate, indicating that these antibodies are directed against 
Table 1.1. Characteristics o monoclona antibodies (Mab) produced against prespore stages o Geratomyxa Shasta.

\begin{tabular}{cccccr} 
& & \multicolumn{2}{c}{$\underline{\text { IFAT } 1 \text { Reactivitv }}$} & & \multicolumn{2}{l}{ Western Blot Reactivitv } \\
Mab & Isotype & prespores spores & & prespores spore sWBCs \\
1 & IgG3 & + & + & + \\
3 & IgGl & + & + & + \\
D8 & IgG2a & + & + & + \\
B1 & IgM & + & +
\end{tabular}

1 Indirect fluorescent antibody test 
Figure I. 1. Western blot analysis showing the patterns of antigen recognition b ymonoclonal antibodies (Mab )D8, B1, and 3 (antigen recognition by Mab 1 was not shown because it was identical to that of Mab 3). Lane representations are : A, molecular weight markers, with weights in kilodaltons to the left of the gel; B, lysates of C .shasta spores, C, lysates of cells from the ascites of infected fish, and D, lysates of trout white blood cells. 


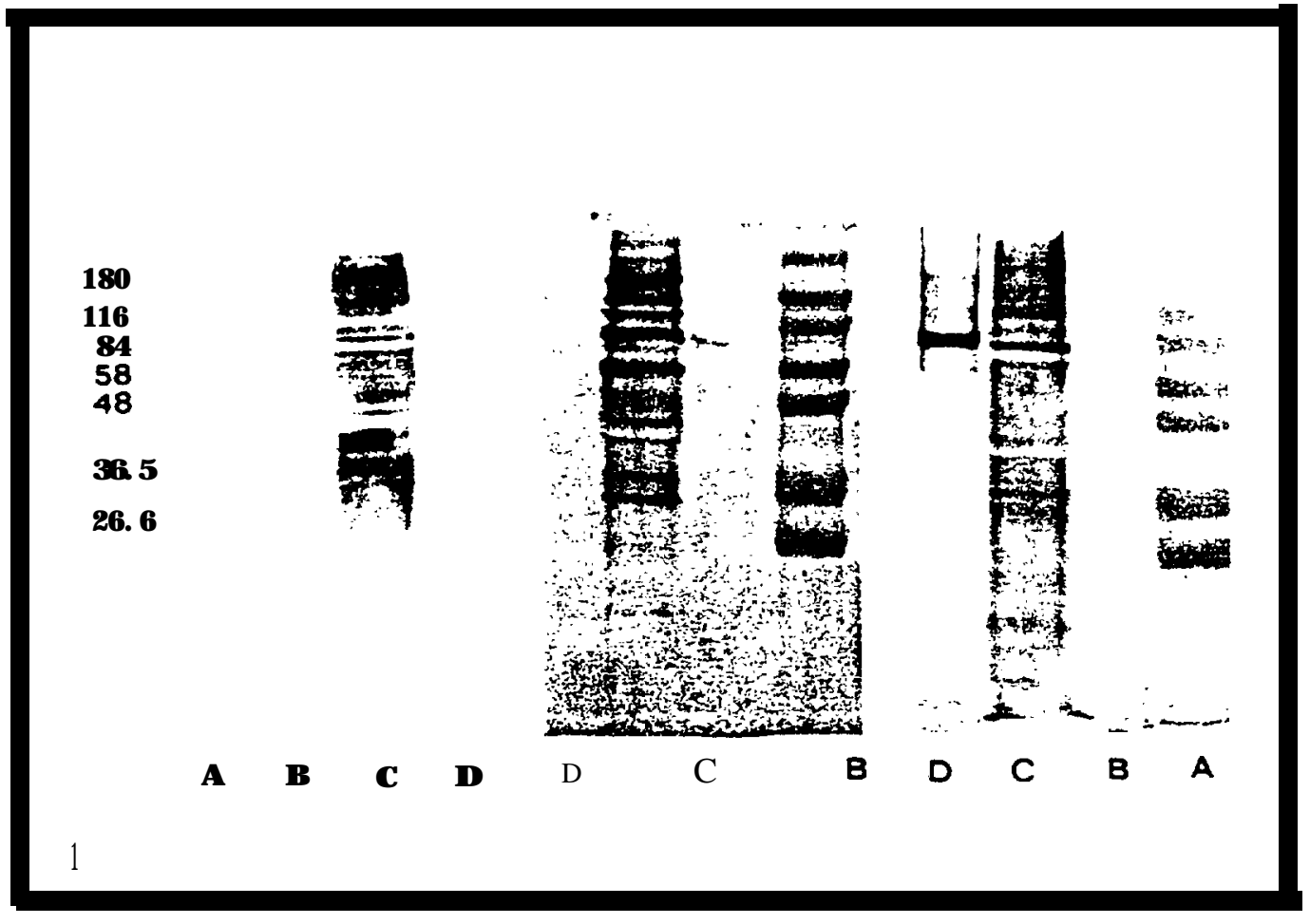


carbohydrate antigens. Binding of Mab D8 to prespore antigens was not inhibited even at the $20 \mathrm{mM}$ periodate concentration.

The cross-reactivity of the monoclonal antibodies with other myxosporeans was examined using IFAT on either histological sections from infected fish or purified spores. Two Mabs, 1 and 3, reacted with Sphaerospora sp. and Myxobilatus sp. from sticklebacks (Gasterosteus sp), and their use resulted in high background fluorescence of fish tissues. Although no specific crossreactivity was detected between Mabs Bl and any myxosporeans, high background flourescence of fish tissues was again noted. Mab D8 did not cross-react with other myxosporeans nor cause nonspecific fluorescence of fish tissues. In addition to reacting specifically to C. shasta in IFATs, Mab D8 was also useful in detecting the parasite when an alkaline phosphatase conjugated second antibody was used (Fig. 1.2).

\section{Polyclonal Antiserum}

The protein chosen as antigen for production of polyclonal antisera was shown by SDS-PAGE to be a major component of $\mathrm{C}$. shasta spores and present in lower concentration in prespore stages (Fig. 1.3). The MW of the purified protein was approximately 84 kdal (Fig. 1.4). Antiserum against this antigen reacted by IFAT to both prespore and spore stages of the parasite, but fluorescence of later life stages was more pronounced (Fig. 1.5). In Western blot analysis the antisera reacted with the $84 \mathrm{kdal}$ protein of both spores and prespores and also with a $180 \mathrm{kdal}$ protein from spores. 
No specific cross-reactivity between the polyclonal antiserum and other myxosporeans was detected by IFAT. 
Figure 1.2. Histological sections of infected rainbow trout intestines showing reaction of Mab D8 with trophozoites (T) by indirect fluorescent antibody techniques (a), and antibody-conjugated alkaline phosphatase (b). 

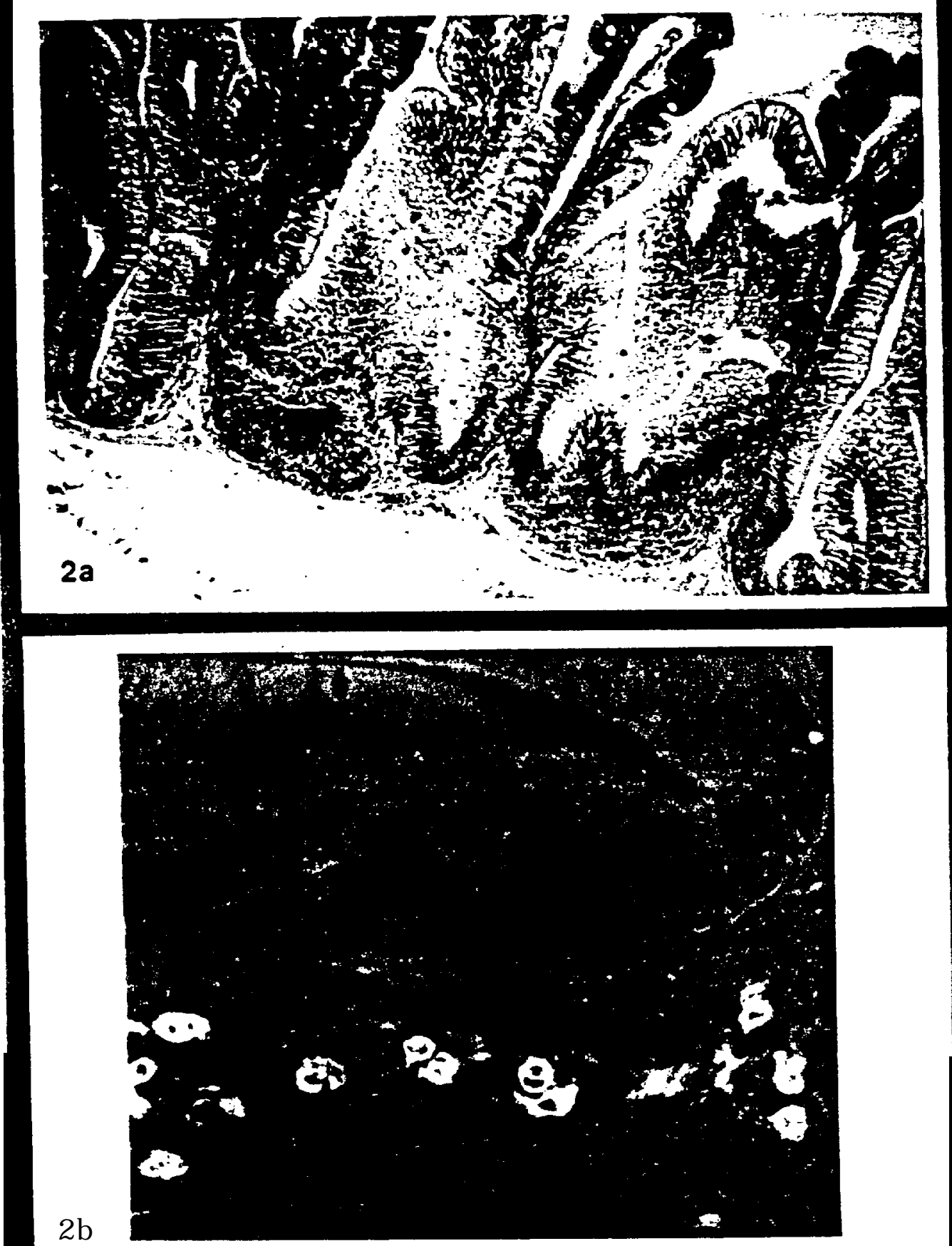
Figure 1.3. SDS-PAGE of lysates of C. shasta spore (B) and prespore (C) stages, and trout white blood cells (D). Weights of molecular weight standards (A) are indicated at left.

Figure 1.4, SDS-PAGE of the C. shasta antigen used for production of polyclonal antiserum (C) and the lysate of spores from which the antigen was purified (B). Weights of molecular weight standards (A) are indicated. 


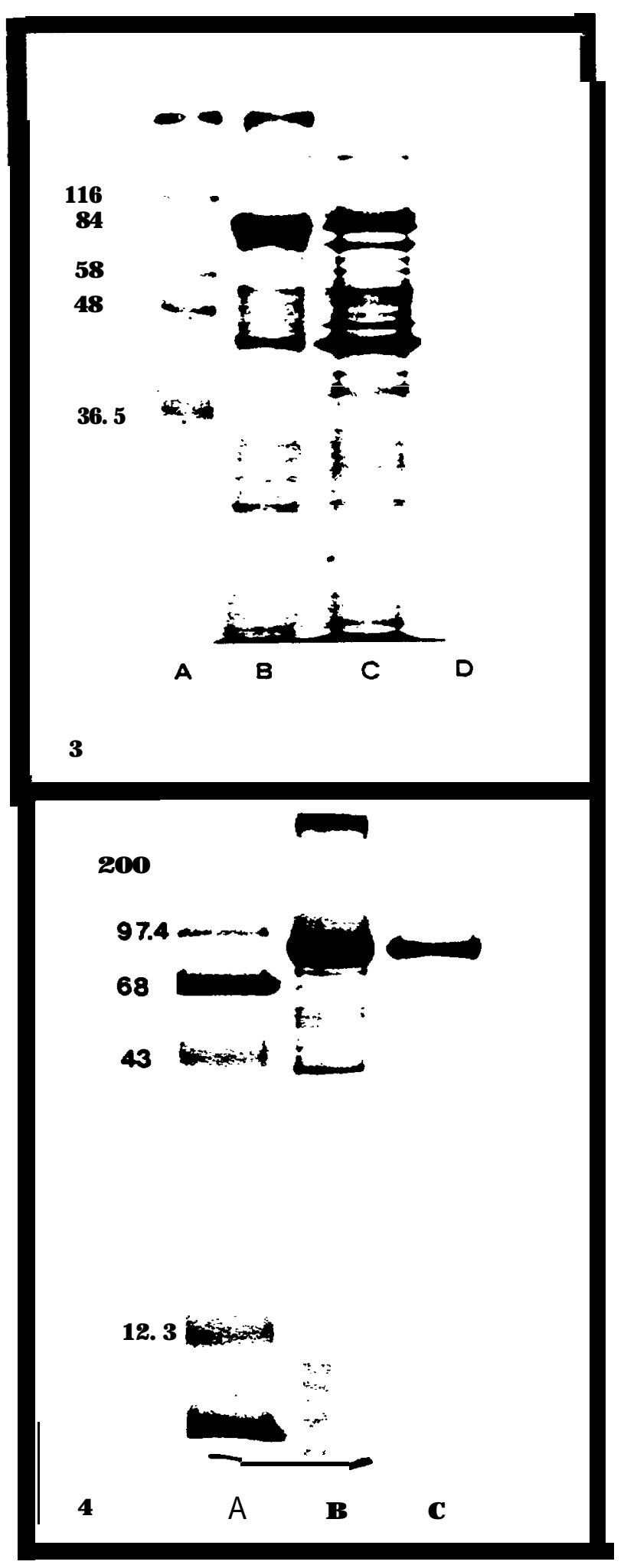


Figure 1.5. Indirect fluorescent antibody reaction of whole spores probed with polyclonal antiserum produced against an antigen from Ceratomyxa shasta spores. 


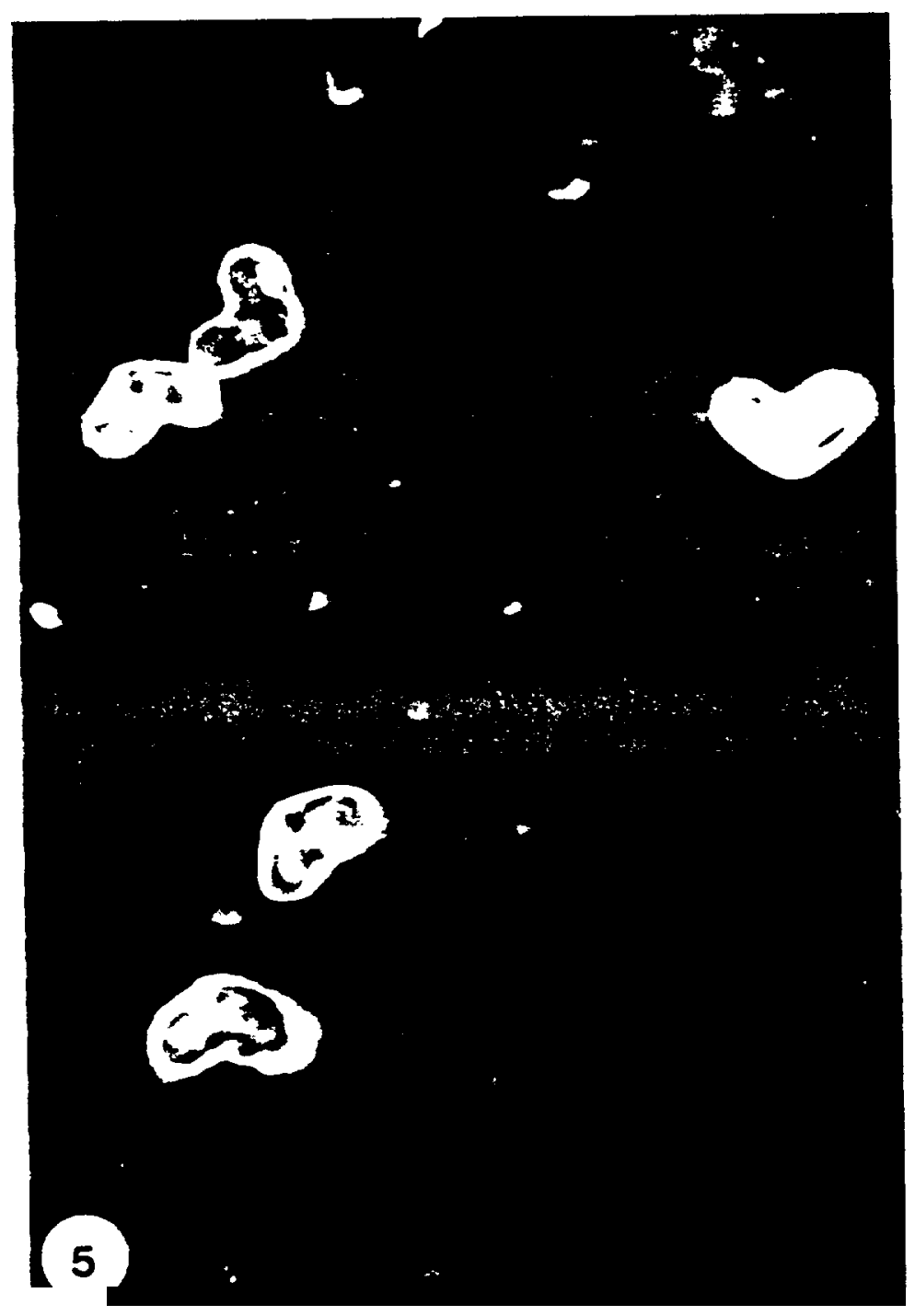




\section{DISCUSSION}

Four hybridomas synthesizing monoclonal antibodies which reacted against trophozoite and disporoblast stages of C. shasta were produced. Reactivity to $\mathrm{C}$. shasta prespore stages was determined by indirect immunofluorescence and by Western blot analysis of electrophoresed trophozoite antigens. None of the hybridomas produced antibodies that reacted with C. shasta spores by dot immunobinding, IFAT, or in Western blots. These data suggest the presence of stage-specific antigens associated with different life stages of C. Shasta. SDS-PAGE analysis demonstrated that some proteins present in high concentration in C. shasta spores are either absent or in low concentration in earlier life stages. It is likely that these noncross-reactive antigens are associated with the formation of the spore coat. Because of difficulties in physically separating C. shasta life stages, all prespore stages were grouped together. This caused some problems in the analysis of electrophoretic profiles because disporoblast stages might have formed some of the antigens found in mature spores.

Two of the hybridomas (Mabs 1 and 3) produced antibodies which cross-reacted with the white blood cell population of uninfected fish and with a high MW protein in fish sera. The crossreacting protein had a MW of approximately $80 \mathrm{kdal}$ and was determined to be fish immunoglobulin heavy chain by Western blot analysis and ELISA. Because no attempt was made to purify $\mathrm{C}$. shasta prespores, it was not unexpected to find antibodies that 
reacted with trout antigens; however, these antibodies were also found to react specifically by IFAT with cells that could be positively identified as C. Shasta. One possible explanation for this cross-reactivity is that $C$. shasta had evoked an immune response and was coated with fish antibody. However, when cells were incubated with fluorescein-conjugated anti-trout Ig there was no reactivity. It has been suggested (Pauley, 1974) that crossreactivity of a specific anti-parasite antibody with uninfected tissue antigens may indicate that an antigenic component of the parasite has been able to mimic normal host antigens and thus evade an immune reaction. Profiles of antibody-antigen recognition seen in Western blots (Fig. 1.1) suggested that the antibodies recognized a common epitope which may indicate the presence of carbohydrate antigens. Mild periodate oxidation, which destroys carbohydrate determinants without affecting either proteins or lipids, caused a complete loss of binding of both Mabs 1 and 3. There has been evidence indicating that antisera produced against phylogenetically distant immunogens may cross-react by virtue of their carbohydrate moities (Bayne et al., 1987; Yamaga et al., 1978). Whether or not this cross-reactivity represents a mechanism by which the parasite avoids the host immune system, the presence of common carbohydrates may be effective in facilitating parasitism by C. Shasta.

In addition to Mabs which reacted with both C. shasta and host antigens, we also produced one monoclonal antibody specific for the prespore stages of the parasite. Hybridoma D8 secreted 
antibodies which did not recognize any other myxosporeans and which were effective in detecting low numbers of C. shasta both in histological sections and in smears of intestinal material from infected fish. Its specificity makes it suitable for use as a diagnostic reagent, either in the IFAT or in enzyme immunohistochemistry. In addition to its applications in diagnostics, this Mab will be useful in studying the life history and pathogenesis of this parasite.

The polyclonal antiserum produced against an antigen predominant in the spore stage of $\mathbf{C}$. shasta was shown by IFAT to react most specifically with these later life stages. This provides additional evidence for the presence of stage-specific antigens associated with the parasite. The abundance of this antigen in the spore makes it a good candidate for production of either monoclonal or polyclonal antibodies against a single defined antigen. The production of these antibodies may be useful not only in diagnostics, but in understanding the biology of C. shasta. 


\section{ACKNOWLEDGEMENTS}

We thank Cindy Arakawa for her assistance in the production and screening of the hybridomas and Mary Arkoosh for testing the Mabs in the ELISA. This research was supported by Bonneville Power Administration under contract No. DE-A179-83 BP 11987; G. R. Bouck, Contracting Officer's Technical Representative. Oregon Agricultural Station Technical Paper No. 8568. 


\section{LITERATURE CITED}

Andrysiak, P. M., W. E. Collins, and G. H. Campbell. 1986. Stagespecific and species-specific antigens of Plasmodium vivax and Plasmodium ovale defined by monoclonal antibodies. Infect. Immun. 54:609-6 12.

Bayne, C. J., C. A. Boswell, and M. A. Yui. 1987. Widespread antigenic cross-reactivity between plasma proteins of a gastropod, and its trematode parasite. Dev. Comp. Immunol. 11:321-329.

Campbell, A.M. 1984. Monoclonal antibody technology, In:

Laboratory Techniques in Biochemistry and Molecular Biology (ed. by Burton R. H. and P. H. van Kippenberg). Vol. 13 . Elsevier Science Publishers, Amsterdam.

Hawkes, R., E. Niday, and J. Gordon. 1982. A dot-immunobinding assay for monoclonal and other antibodies. Anal. Biochem. 119:142.-147.

Johnson, K. A., J. E. Sanders, and J. L. Fryer. 1979. Ceratomyxa Shasta in salmonids. U.S. Dep. Int. Fish. Wild. Serv., Div. Fish. Res. Fish Disease Leafl. No. 58:1lp.

Pauley, G. B. 1974. Fish sporozoa: extraction of antigens from Myxosoma cerebralis spores which mimic tissue antigens of rainbow trout (Salmo gairdneri). J. Fish. Res. Board Can. 31:1481-1484.

Schleif, R. F., and P. C. Wensink. 1981. Practical methods in molecular biology. Springer-Verlag. New York.

Udey, L. R., J. L. Fryer, and K. S. Pilcher. 1975. Relation of water temperature to ceratomyxosis in rainbow trout (Salmo gairdneri) and coho salmon (0 ncorhynchus kisutch). J. Fish. Res. Board Can. 32:1545-1551.

Wolf, K., and M. E. Markiw. 1984. Biology contravenes taxonomy in the myxozoa: new discoveries show alternation of invertebrate and vertebrate hosts. Science 2:1449-1452. 
Woodward, M. P., W. W. Young, Jr., and R. A. Bloodgood. 1985. Detection of monoclonal antibodies specific for carbohydrate epitopes using periodate oxidation. J. Immunol. Methods 78:143-153.

Wrightsman, R. A., W. Leon, and J. E. Manning. 1986. Variation in antigenic determinants specific to the infective stage of Trypanosoma cruzi. Infect. Immun. 53:235-239.

Yamaga. K. M., R. T. Kubo, and H. M. Etlinger. 1978. Studies on the question of conventional immunoglobulin on thymocytes from primitive vertebrates: II. Delineation between Ig-specific and cross-reactive membrane components. J. Immunol. 120:2074-2079. 
CHAPTER II

CHARACTERIZATION OF THE HOST RESPONSE TO THE MYXOSPOREAN PARASITE, CERATOMYXA SHASTA, BY HISTOLOGY, SCANNING ELECTRON MICROSCOPY, AND IMMUNOLOGICAL TECHNIQUES

J. L. Bartholomew I, C. E. Smith ${ }^{2}$, J. S. Rohovecl, and J. L. Fryer 1

1 Department of Microbiology Oregon State University Corvallis, Oregon 97331

2Fish Technology Center US Fish and Wildlife Service Bozeman, Montana 59715 


\section{ABSTRACT}

The tissue response of Salmo gairdneri against the myxosporean parasite, Ceratomyxa shasta, was investigated using histological techniques, scanning electron microscopy, and immunological methods. The progress of infection in $\mathrm{C}$. Shasta-susceptible and resistant steelhead and rainbow trout was examined by standard histological techniques and by indirect fluorescent antibody methods using monoclonal antibodies directed against C. shasta antigens. Trophozoite stages were first observed in the posterior intestine and there was indication that resistance was due to the inability of the parasite to penetrate this tissue rather than to an inflammatory response. Examination of a severely infected intestine by scanning electron microscopy showed extensive destruction of the mucosal folds of the posterior intestine. Western blotting and indirect fluorescent antibody techniques were used to investigate the immunological component of the host response. No antibodies specific for C. shasta were detected by either method. 


\section{INTRODUCTION}

Ceratomyxa shasta is a histozoic myxosporean which parasitizes the intestinal tissues of salmonids. Its geographic range is limited to northern California and the Pacific Northwest region of the United States and Canada (Hoffmaster et al., 1988). The parasite is an important cause of mortality among susceptible salmonids. Fish are infected while in fresh water; however, anadromous salmonids may continue to die of ceratomyxosis during the salt water phase of their life cycle (Ching and Munday 1984). The life cycle of C. shasta has not been defined, but its apparent discontinuous distribution and the difficulty in achieving laboratory transmission of the infectious agent suggests that one or more unknown factor(s) is required. The involvement of an intermediate host has been suggested; however, no life cycle has been proposed.

Initial signs of infection by C. shasta may include darkening, lethargy, and loss of appetite. As the disease progresses, the descending intestine and anus become swollen and hemorrhagic and ascites may collect in the coelom (Wales and Wolf, 1955; Schafer, 1968; Johnson, 1975). Definitive diagnosis is made by observation of the mature spore in wet mounts or histological sections. However, before sporogenesis is complete, trophozoites can be identified by their multicellular ameboid morphology and characteristic nuclei 
containing a large karyosome and peripheral chromatin (Noble 1944). Multiplication of trophozoites is by nucleogony followed by either budding or plasmotomy (cytoplasmic division)(Noble 1941).

Many reports describe infections of fish by myxosporeans, but the view that most species cause little host response is commonly held. Coelozoic myxosporeans cause little host reaction and have been considered the most harmless (Lom 1970); however, Fantham (1912) described an inflammatory reaction consisting of leucocyte infiltration, desquamation and necrosis of epithelial cells, and increased mucous secretion caused by myxosporeans parasitizing the gall bladder. Lom (1969) also reported hyperemia and hypertrophy associated with coelozoic myxosporeans.

A lack of tissue response has also been attributed to cyst forming myxosporeans (Lom 1969). Dykova and Lom (1978) reported histopathological changes in gills of fish infected with two species of Henneguya and proposed that the tissue response to myxosporeans invading soft tissue occurred in two phases. First, as the plasmodium grew, there occurred alterative changes in the tissue: displacement, atrophy and hyperplasia. Although organ function may have been impaired, there was no host defense reaction. In the second stage, cysts were full of mature spores which evoked an inflammatory reaction leading to replacement of the cyst by granulomatous tissue. Amandi and Fryer (1985) 
recognized a similar host reaction against Myxobolus insidiosus which infects the muscle of salmonids. Contrary to the lack of inflammatory response to immature plasmodia, Duhamel (1986) reported that trophozoites of Henneguya exilis were responsible for severe granulomatous branchitis in channel catfish.

The tissue response against non-cyst forming histozoic myxosporeans is also varied. Myxobolus cerebralis infects young salmonids by invading and causing destruction of cartilage cells. A granulomatous response with infiltration by macrophages and mononuclear leucocytes has been reported (Roberts and Elson 1970; Taylor and Haber 1974; Halliday 1976). Other myxosporeans cause complete degeneration of invaded areas accompanied by hypertrophy of connective tissue cells and invasion by fibroblasts. Kent and Hedrick (1985) described the reaction of salmonids against the etiological agent of proliferative kidney disease as a granulomatous nephritis with an infiltration of macrophages and mononuclear cells and suggested that the severity of the inflammatory reaction is because salmonids are abnormal hosts for this myxosporean.

Investigations of the immune component of the host reaction against myxosporeans has produced varied results. Some researchers (Lom 1969; Dykova and Lom 1978) suggest that regression of Henneguya infections at high temperatures is probably caused by an increase in antibody production and 
enhanced cellular defenses. However, Siau (1980) found no antibody response in Mugil immunized with Myxobolus exiguus by gel precipitation or complement fixation assays. Halliday (1974) and Pauley (1974) were unable to detect antibodies to Myxobolus cerebralis spores in either naturally infected or immunized fish. Halliday suggested that a lack of antibody response indicates either a privileged site of infection or non-pathogenicity of the spore stage. Pauley presented evidence suggesting that parasite antigens mimic host antigens. However, Griffin (1978) was able to detect trout antibodies against $M$. cerebralis spores by an indirect fluorescent antibody test.

The host range of C.. shasta includes a number of salmonid species; however, different strains of the same species vary in susceptibility to the disease. Development of resistance appears to be a selective factor in waters where C. shasta is present (Johnson 1975; Zinn et al., 1977; Buchanan et al., 1983). Fish from watersheds endemic for the parasite are resistant but those from areas free of C. shasta are susceptible and may experience serious mortality when exposed to the infective stage of the organism. In this study the histopathology of infection was observed in resistant and susceptible strains of salmonids, the immune reaction of the host was investigated, and a scanning electron microscopic examination was made of a heavily infected intestine. 


\section{MATERIALS AND METHODS}

\section{Infection of Fish.}

Two strains of steelhead trout (Salmo gairdneri), C. Shasta-susceptible Siletz River and C. Shasta-resistant North Santiam, were exposed simultaneously to the infective stage of C. shasta for three days in the Willamette River at Corvallis, Oregon. One hundred-fifty fish (1-4 $\mathrm{g}$ in weight) of each strain were exposed to the parasite. During the three days in the river, 10 fish were removed from each group at each of eight sampling periods which were $30 \mathrm{~min}$, and $1,2,4,8,24$, 48, and $72 \mathrm{~h}$. After three days, the remaining fish were returned to holding tanks and maintained at $120 \mathrm{C}$ in a pathogen-free water supply. Fish were taken at 5, 8, 18, and 30 days post-exposure. From each exposure period, five whole fish were fixed in Bouin's fixative and five in $10 \%$ neutral buffered formalin. Unexposed control fish from each strain were obtained in the same manner.

Susceptible Shasta rainbow trout (Salmo gairdneri) were exposed to the parasite as described; however, following the three day exposure they were held at 210C. Ten fish were removed at each of the following time intervals: 0,2 , and 8 hours, and 1, 2, 4, 7, 10, 14, 18, and 20 days. Visceral organs and gills of the fish were removed and fixed in either Bouin's or $10 \%$ neutral buffered formalin. Additionally, two sets of 
blood smears and kidney imprints were made from each fish; one set was fixed in Schaudinn's fixative and stained with May-Gruenwald Giemsa and one set was air dried and methanol fixed for examination by fluorescent antibody techniques.

\section{Preparation and Examination of Specimens for Histology.}

Whole fish and organs were embedded in paraffin, sectioned, and mounted on gelatin coated slides. Sections for light microscopy were stained with either May-Gruenwald Giemsa or haematoxylin-eosin (H\&E). Sections were also examined serologically using either indirect fluorescent antibody techniques (IFAT) or alkaline phosphatase (AP) immunoenzymatic staining techniques. For both immunos taining procedures, sections were deparaffinized in two, $15 \mathrm{sec}$ changes of xylene and hydrated in three, $15 \mathrm{sec}$ changes of $95 \%$ ethanol followed by two, 5 min washes in phosphate buffered saline (PBS). Sections and methanol fixed smears and imprints were incubated with monoclonal antibodies directed against antigens of C. shasta trophozoites (Bartholomew et al., submitted), then with biotinylated horse anti-mouse IgG (diluted 1:10O in PBS)(Vector Laboratories, Burlingame, CA). Slides to be examined by IFAT were incubated with fluorescein isothiocyanate-conjugated avidin D 
(diluted 1:200 in PBS)(Vector Laboratories), counterstained with methyl green dye (1\% in distilled water), and examined using a Zeiss standard microscope with an IV Fl epifluorescence condensor. Sections to be labeled immunoenzymatically were incubated with avidin DHbiotinylated AP H complex (Vector Laboratories). The enzymatic activity was localized with an insoluble substrate (Alkaline Phosphate Substrate Kit II; Vector Laboratories) which was visualized by bright light microscopy.

\section{Preparation and Examination of Specimens for Scanning Electron Microscopy}

Intestines from three heavily infected and one uninfected Shasta rainbow trout were dissected and fixed in $3 \%$ glutaraldehyde in cacodylate buffer $\mathrm{pH} 7.0,0.2 \mathrm{M}$ for $3 \mathrm{~h}$ then transferred through solutions of increasing concentrations of acetone in water and trichlorofluroethane (TF) in acetone, $30 \mathrm{~min}$ per change. From absolute TF, tissues were critical point dried following the method of Cohen et al. ( 1968) in a Balzers CPD $020 \mathrm{CP}$ dryer. Specimens were then mounted on aluminum plancets using DUCO adhesive and coated with 200 A of 60:40 wt \% Au:Pd alloy in a Varian VE10 vacuum evaporator of $1 \times 10-5$ Torr. Examination was made using an AMRAY 1000A SEM, operated at $20 \mathrm{kv}$. 


\section{Detection of Antibody Response.}

Shasta rainbow trout were exposed to the infective stage of C. shasta for three days, returned to holding facilities, and held at 150C. When signs of infection were evident, fish were killed, bled, and examined for presence of the parasite. Blood from positive individuals was pooled, allowed to clot at room temperature, and the serum was collected. Antibodies were detected by Western blotting, using electrophoresed spore and prespore proteins as antigen. Following electrophoretic separation of these antigens on a $12 \%$ sodium dodecyl sulfate-polyacrylamide gel, they were transferred onto nitrocellulose by electroblotting in a Trans-blot cell (BioRad Laboratories, Richmond, CA). The nitrocellulose was then probed with the fish antiserum, mouse monoclonal antiserum produced against trout immunoglobulin (cell line 1-14, a gift of Dr. G. Warr, Dept. of Biochemistry, Univ. of South Carolina), and finally with goat anti-mouse antibodies conjugated with horseradish peroxidase (Hyclone Laboratories, Logan, Utah).

Attempts were also made to detect trout immunoglobulin on the surface of trophozoites. Methanol fixed smears of trophozoites in ascites were examined by IFAT as described previously, using monoclonal antibodies directed against trout immunoglobulin as the primary antibody. 


\section{RESULTS}

\section{Histopathology in Salmonids Susceptible to Infection by Ceratomyxa shasta.}

Infection by C. shasta in Siletz River steelhead trout was first detected $18 \mathrm{~d}$ post-exposure when fish were held at $12^{\circ} \mathrm{C}$. Trophozoites were first seen in the descending intestine and were located between or at the base of mucosal epithelial cells. An inflammatory response, consisting of an infiltration of lymphocytic cells, was usually seen in the submucosa adjacent to the trophozoites (Fig. 11.1). These foci were easily detected in histological sections stained by Giemsa or $H \& E$ and the identity of the trophozoites was confirmed by IFAT. The number of foci was limited and mucosal folds adjacent to the infected site appeared normal. The epithelium was usually intact, but cell nuclei showed signs of karyolysis and cells were often necrotic (Fig. 11.2).

By $30 \mathrm{~d}$, the entire intestinal tract was infected and trophozoites were proliferating in all layers of the mucosa, the submucosa, and in the muscularis (Fig. 11.3). Trophozoites were diffusely scattered throughout the tissues and were surrounded by necrotic host cells (Fig. 11.4). The lamina propria was thickened due to the inflammatory response and numerous parasites. The epithelium was no longer intact; epithelial cells were rounded and many had pycnotic nuclei. 
Many cells had sloughed so that trophozoites and necrotic epithelial cells were present in the lumen of the intestine. Trophozoites penetrated the muscularis and serosa and invaded the adjacent adipose tissue in the coelomic cavity. Trophozoites were not found in the stomach, pyloric caeca, spleen, pancreas, or kidney but they were found in the blood sinusoids of the liver. Trophozoites were present in the gill capillaries and epithelial tissue of one fish (Fig. 11.5).

Fish began to die at $52 \mathrm{~d}$ post-exposure and it was at this time that spores were first noted. Portions of the descending intestine were severely necrotic and completely occluded. Fibroblasts formed a network which enmeshed trophozoites, lymphocytes, and necrotic host cells. Exudative material was found throughout the intestine and the ascending intestine, pyloric caeca, and stomach were heavily infected. Trophozoites were present in all layers of the pyloric caeca; in some sections the epithelial cells were intact and in others they were sloughed and caeca were occluded (Fig. II.6 and 11.7). Adipose tissue surrounding the caeca was destroyed and the pancreatic tissue heavily infected and sometimes necrotic. Trophozoites were found in hematopoietic tissue of the kidney; also, in the kidney tubules, between epithelial cells and in their lumens (Fig. 11.8). Foci of infection were seen in the liver, some were necrotic with exudative material and others were characterized by a lymphocytic infiltration. Proliferating trophozoites were observed throughout the organ and sporogenesis was occurring (Fig. 11.9). 
Figure II. 1. Section of intestinal tissue from a susceptible Siletz River steelhead trout showing an inflammatory response (arrow) $18 \mathrm{~d}$ after exposure to the infective stage of Ceratomyxa Shasta. H\&E stain, 100X.

Figure 11.2. Ceratomyxa shasta trophozoites (arrows) in the mucosal epithelium at $18 \mathrm{~d}$ post exposure. Giemsa stain, 1000X.

Figure 11.3. Intestinal tract at $30 \mathrm{~d}$ post-exposure. Trophozoites are proliferating in all intestinal layers and portions of the mucosal epithelium have sloughed. Giemsa stain, $100 \mathrm{X}$.

Figure 11.4. Trophozoites (arrows) are diffusely scattered throughout the tissues and are surrounded by necrotic host cells. Epithelial cells are rounded (white arrow) and are being sloughed. Giemsa stain, 250X.

Figure 11.5. Trophozoites in the gill capillary and adjacent epithelial tissue (arrows). Giemsa stain, 40X.

Figure 11.6. Infected pyloric caeca and surrounding adipose and pancreatic tissue $52 \mathrm{~d}$ post-exposure. Muscularis of caeca is infected. Note necrosis and sloughing of mucosal epithelium from underlying submucosa. Giemsa stain. $250 \mathrm{X}$.

Figure 11.7. Severe necrosis and occlusion of the lumen of a pyloric caeca. Numerous trophozoites are multiplying in all tissue layers. Giemsa stain, 400X. 


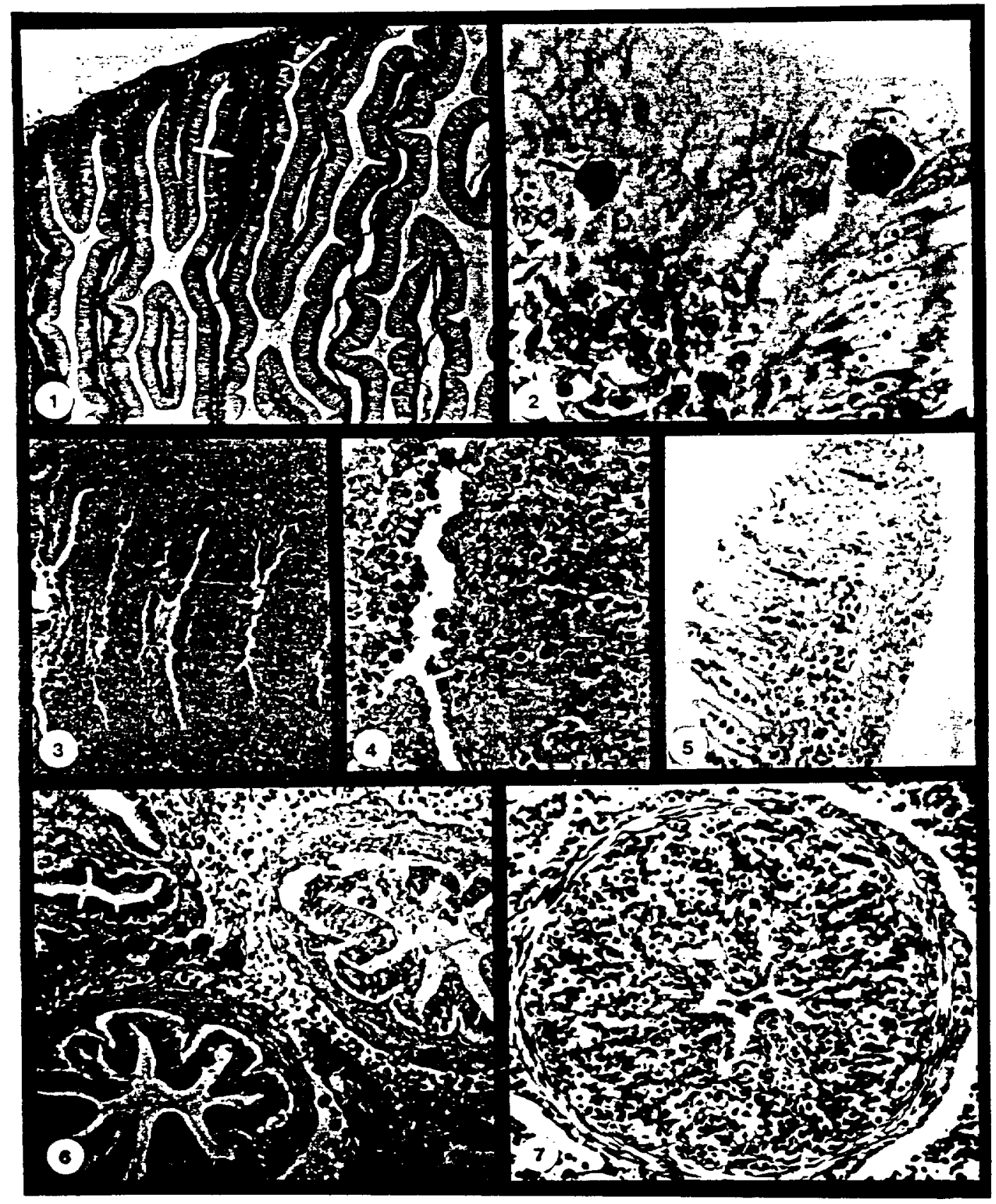


Figure 11.8. Kidney of Siletz River steelhead trout $52 \mathrm{~d}$ postexposure. Trophozoites (white arrows) are present in the hematopoietic tissue and in necrotic kidney tubules (black arrows). Giemsa stain, 250X.

Figure 11.9. Liver tissue at $52 \mathrm{~d}$ showing area of focal necrosis. Trophozoites proliferated throughout the tissue and sporogenesis was occurring (arrows). Giemsa stain, $250 X$. 


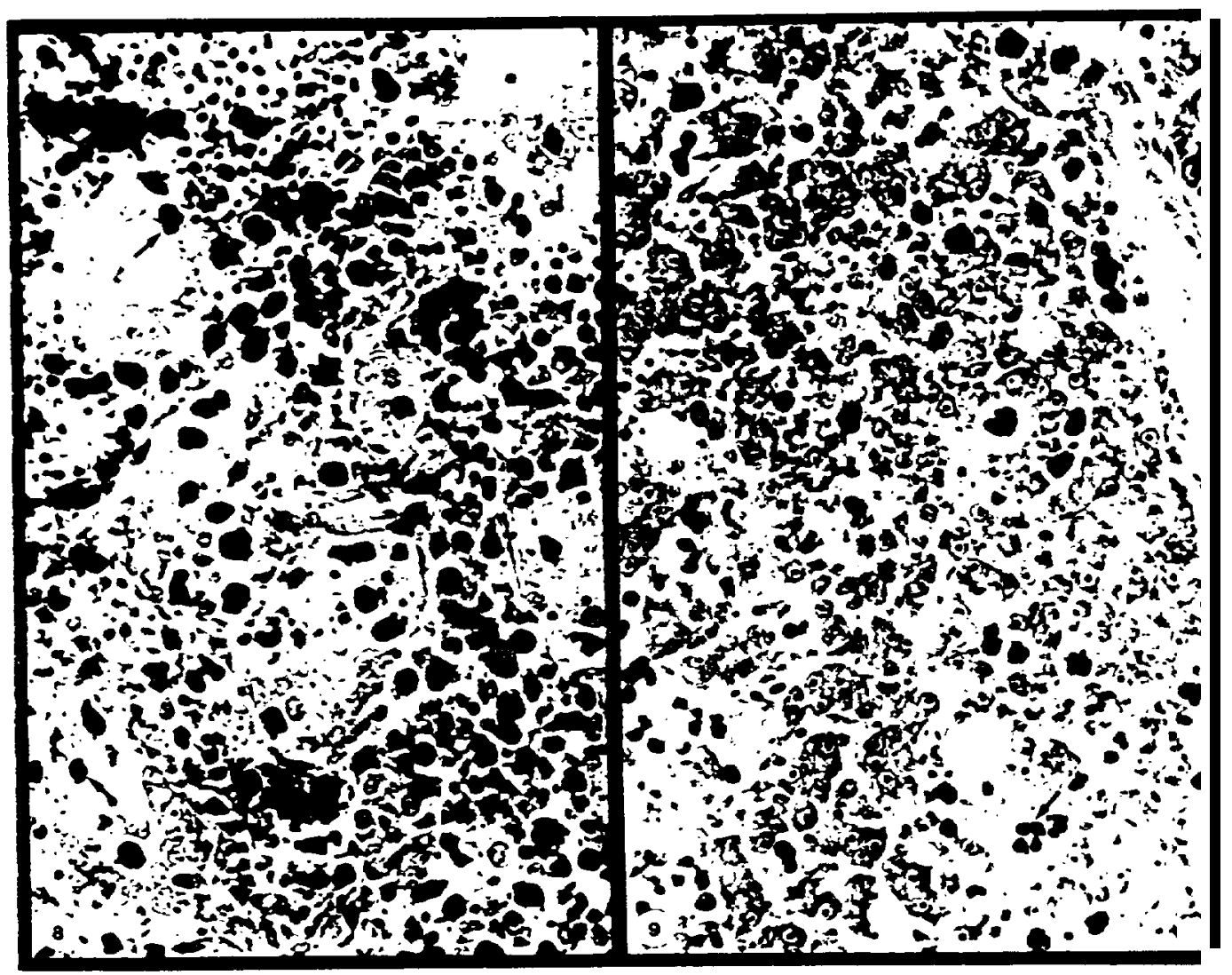


In Shasta rainbow trout held at $210 \mathrm{C}$ after exposure to the infective stage, the parasite was first detected at $7 \mathrm{~d}$ post-exposure. Trophozoites were most easily detected by IFAT because of limited inflammation (Fig. II. 10). Multicellular trophozoites were detected mainly at the base of epithelial cells in the posterior intestine and some were also observed in hepatic blood sinusoids (Fig. II.1 1). By $10 \mathrm{~d}$, focal inflammatory reactions had developed in some fish and trophozoites were detected between epithelial cells or in the submucosa of the inflamed area. Parasites were observed throughout the posterior intestine (Fig. 11.12) and some appeared in the anterior intestine and connective tissue surrounding blood vessels in the pancreatic tissue. The livers of several fish were also infected and hepatic cells were undergoing degeneration. Fish sampled at 14 and $18 \mathrm{~d}$ post-exposure showed varying degrees of infection and host response. Intestines were mildly to severely infected and lumens were occluded in certain areas (Fig. II. 13). In severely infected fish, trophozoites proliferated in the mucosa, submucosa, muscularis, and serosa. Infected tissues were hemorrhaged and infiltrated by eosinophilic granular leucocytes and lymphocytes. The epithelium was necrotic and had sloughed in certain areas so that necrotic host cells and trophozoites were observed in the intestinal lumens. Parasites penetrated the muscularis and serosa and were free in the peritoneal cavity. Adipose tissue adjacent to the intestine was parasitized and infiltrated by lymphocytes and there was a hyperplasia of connective tissue (Fig. 11.14). At 18 d, sporogenesis was evident in 
the intestine. The muscularis of the pyloric stomach was infected and trophozoites were separating muscle fibers, leaving spaces filled with necrotic material (Fig. 11.15). Nuclei of smooth muscle fibers were pycnotic and the fibers were degenerating. Pyloric caeca in close proximity to the infected stomach and intestine were also infected (Fig. 11.16). Although trophozoites penetrated the submucosa, muscularis, and serosa of these tissues, the epithelium was still intact in certain areas. The liver in most fish had sites of focal infection (Fig. II. 17). Hepatocytes were necrotic and lymphocytes infiltrated the infected tissues. Blood smears and kidney imprints were also positive for trophozoites (Fig. II.18 and 11.19). The spleen remained uninfected. At $20 \mathrm{~d}$ post-exposure, as fish were dying of the disease, intestinal lumens were completely occluded and most adjacent tissues and organs were infected to varying degrees. The cardiac stomach and spleen remained uninfected.

One Shasta rainbow, sampled at $18 \mathrm{~d}$ post-exposure, did not show typical histopathology. In this fish, trophozoites were observed in the lumen of the intestine and within the epithelial layer (Fig. 11.20 and 11.21). Those in the lumen were both free and attached to the epithelial surface. There was no inflammatory inflammatory response. The identity of these trophozoites as early stages of C. shasta was confirmed by IFAT. 
Figure II. 10. Fluorescent antibody stain of intestinal tissue fom Shasta strain rainbow trout $7 \mathrm{~d}$ post-exposure showing a multicellular trophozoite in the mucosal epithelium. $400 \mathrm{x}$.

Figure II. 11. Trophozoite (arrow) in the blood sinusoids of the liver at 7 d. Giemsa stain, 1000X.

Figure II. 12. Intestine at $10 \mathrm{~d}$ with parasites (arrows) in or at the base of the mucosal epithelium. Alkaline phosphatase immunostain, 100X.

Figure II. 13. Occluded lumen of posterior intestine from a Shasta strain rainbow trout sampled $18 \mathrm{~d}$ post-exposure. Epithelial cells are necrotic and sloughed and trophozoites exist in all intestinal layers. Giemsa stain, $100 \mathrm{X}$.

Figure II. 14. Adipose tissue (A) adjacent to the intestinal serosa $(\mathrm{S})$. The intestine has been penetrated, there is hemorraghing, and trophozoites (arrows) are multiplying in the adipose tissue. Giemsa stain, $250 X$.

Figure 11.15. Trophozoites (arrows) in the muscularis of the stomach were found between muscle fibers. Giemsa stain, 400X.

Figure II. 16. Infected stomach and adjacent pyloric caeca. Trophozoites appear in all tissue layers but the epithelium is intact. Giemsa stain, 100X.

Figure II. 17. Liver at $14 \mathrm{~d}$ post-exposure showing numerous trophozoites (arrows). Giemsa stain, 250X.

Figure II. 18. Blood smear with multicellular trophozoite (arrow) surrounded by blood cells. Giemsa stain, 400X.

Figure II. 19. Trophozoite (arrow) in kidney imprint. Giemsa stain, $400 x$. 


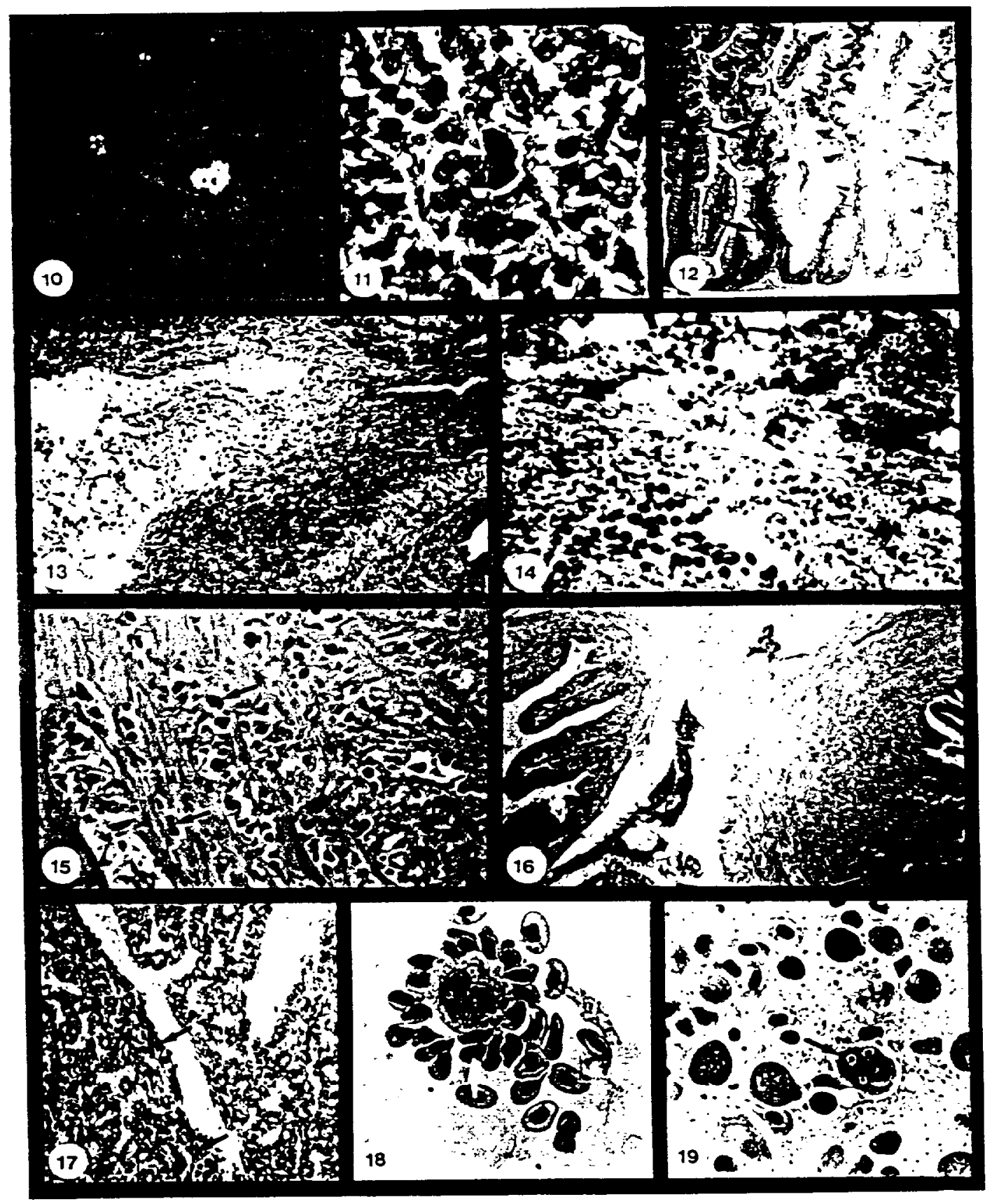


Figure 11.20. Trophozoites (arrows) in the lumen of the intestine of a Shasta strain of rainbow trout $18 \mathrm{~d}$ post-exposure. Giemsa stain, 100X.

Figure II.2 1. Trophozoite (arrow) on the surface of the intestinal mucosal epithlium. Giemsa stain, 400X.

Figure 11.22. Trophozoite in the lumen of the intestine of a North Santiam strain steelhead trout $30 \mathrm{~d}$ post-exposure. Giemsa stain, 250X. 


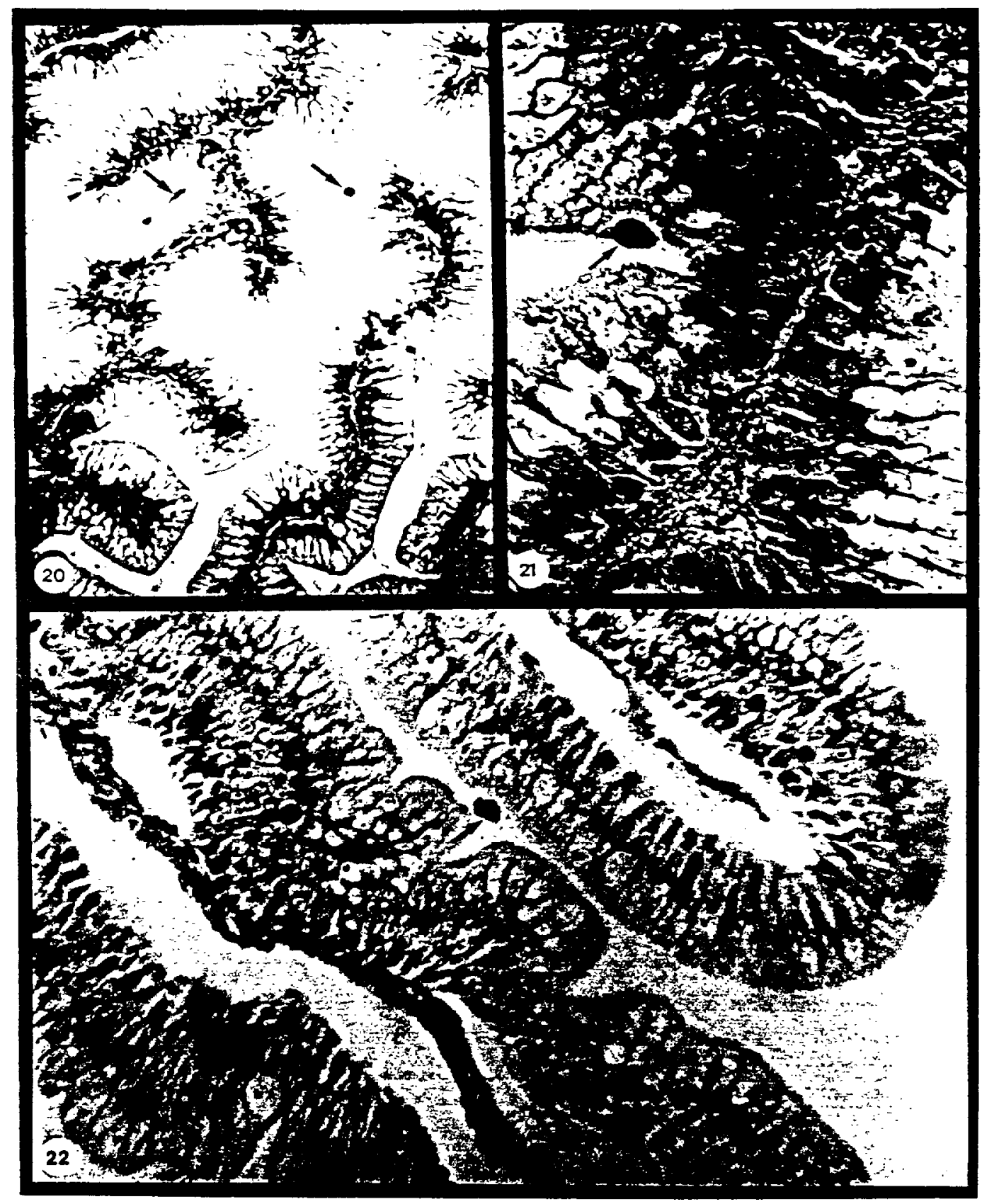




\section{Histopathology of Infection in Salmonids Resistant to Ceratomyxa Shasta.}

Ceratomyxa shasta was detected in only two resistant fish, both at $30 \mathrm{~d}$ post-exposure. In one fish, a single trophozoite was observed in the lumen of the posterior intestine (Fig. 11.22). It was not attached and there was no sign of a host response. The second fish was severely infected. Trophozoites had penetrated the intestinal epithelium and the infection appeared the same as in severely infected susceptible fish.

\section{Scanning Electron Microscopy.}

Comparison of infected and uninfected posterior intestines by scanning electron microscopy showed complete destruction of the mucosal epithelium and different degrees of damage to the structure of the mucosal folds in infected fish (Fig. II.23 - 11.28). Lymphocytes, macrophages, and red blood cells were numerous in infected areas. Sporogenesis was also observed. Desquamation of the columnar epithelial cells caused loss of secondary structures of the folds and in 
Figure 11.23. Scanning electron micrograph of the posterior intestine from an uninfected control fish showing parallel mucosal folds with secondary folds. Bar indicates scale in micrometers.

Figure 11.24. Posterior intestine of an infected fish at the same magnification. The secondary structure of the mucosal folds has been destroyed in the lower portion, and there is little left of any primary structure in some areas (arrow). Bar indicates scale in micrometers.

Figure 11.25. Control intestine, showing smooth mucosal folds. Outlines of columnar epithelial cell surfaces are visible. Bar indicates scale in micrometers.

Figure 11.26. Infected intestine at the same magnification. Destruction of the intestinal mucosa and penetration into the underlying layers. Little identifiable structure remains except at the top of the folds, where trophozoites and inflammatory cells are not as numerous. Bar indicates scale in micrometers.

Figure 11.27. High magnification of the mucosal surface in an uninfected fish. Outlines of cell surfaces are visible. Depressions mark the pores of discharging mucous cells. Bar indicates scale in micrometers.

Figure 11.28. High magnification of an infected intestine showing extreme tissue damage. A variety of cell types are present, including lymphocytes, red blood cells, and C. Shasta trophozoites and spores (arrow). Bar indicates scale in micrometers. 


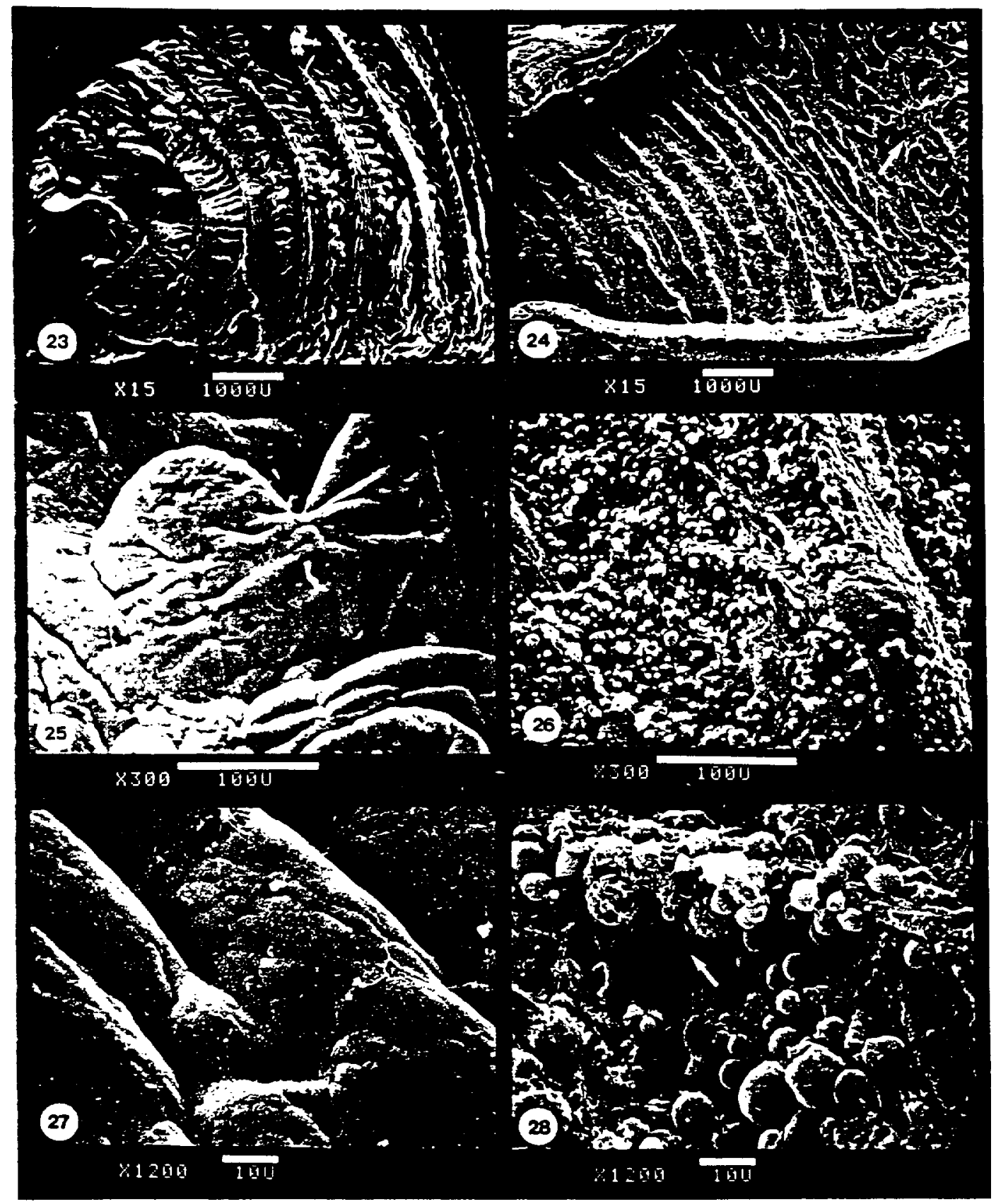


certain areas the underlying connective tissues were also destroyed.

\section{Antibody Response.}

The antibody response of naturally infected rainbow trout was investigated by Western blot analysis and IFAT. Specific antibody against C. shasta was not detected by either method. 


\section{DISCUSSION}

Myxosporeans are generally known to parasitize fish without damaging tissues; however, certain species cause extreme tissue reactions and death of the host. In concurrence with this, descriptions of host responses to these parasites range from a complete lack of tissue reaction to a severe inflammatory response. Ceratomyxa shasta belongs to this latter group, causing extensive intestinal damage and death in susceptible salmonid fishes.

The first location that trophozoites were detected was between epithelial cells of the descending intestine. This observation was in agreement with that of Yamamoto and Sanders (1979). Although Johnson (1975) suggested that the pyloric caeca were the primary site of infection, we did not detect trophozoites in this tissue by examination of Giemsa stained sections or by IFAT until late in the infectious process. Furthermore, Johnson's descriptions of trophozoites in the pyloric caeca did not coincide with those of trophozoites in the intestine, suggesting that they may not have been the same organism. The inability to detect C. shasta until $7 \mathrm{~d}$ post-exposure in fish held at $210 \mathrm{C}$ suggests that very few organisms are required to initiate infection. An alternate explanation is that the infective stage may enter the fish by a route other than the intestine and was not observed using our detection methods.

A vigorous host response, consisting mainly of a lymphocytic infiltration, accompanied the proliferation of parasites in the 
intestine. The observation of an inflammatory response against these early stages differs from the observation of Dykova and Lom (1978) that inflammatory reactions occur only with the development of mature spores. However, their conclusions were based on examining the pathology caused by cyst-forming histozoic species. The trophozoite is the pathogenic stage of this parasite and once established in the host is proteolytic and invasive.

Although C. shasta has a trophism for the intestine, it differs from the tissue specificity shown by most myxosporeans by effectively invading and multiplying in most other tissues and organs. Noble (1950) noted the parasite in the entire alimentary tract, gill capillaries, kidney, spleen, liver, gall bladder, and gonads; Schafer (1968) reported infections of the eyes; Conrad and DeCew (1966) found the parasite in muscle; and Margolis and Evelyn (1975) reported lesions in the kidney, pyloric caeca, intestine and on the flanks below the dorsal fin. Trophozoites multiply extensively in the intestinal tract and several days after initial detection, they are present in the mucosa and submucosa throughout the intestine.

In this study, appearance of trophozoites in the liver closely followed their presence in the intestine. The route of invasion into the liver was probably venous blood which enters the hepatic portal system directly from the alimentary tract. Blood transport via the hepatic portal system was also observed by Jakowska (1979) for Henneguya species. While necrotic degradation and 
inflammatory responses were seen in the hepatic tissues, this organ was not as extensively infected as the alimentary tract.

The infection proceeded anteriorly in the intestine, but at the same time it penetrated the muscularis and serosa and became free in the peritoneal cavity. This made it difficult to determine whether the caeca became infected internally or by penetration of the serosa from the outside. It is possible that both occur, as some caeca were infected only in the muscularis and serosa and had an intact epithelium, while other caeca were completely destroyed. Adipose and pancreatic tissue adjacent to the pyloric caeca were also infected. Penetration of the stomach did appear to be external or via the bloodstream, as trophozoites were always found between muscle layers while the mucosa was intact, with no parasites or inflammation.

At the same time that trophozoites penetrated the intestinal wall, they were also detected in blood smears and kidney imprints. The presence of C. shasta in the bloodstream allowed its spread to other tissues and organs which had not been penetrated by the parasite from the body cavity.

Scanning electron microscopic studies of heavily infected posterior intestines allowed assessment of the amount of structural damage caused by this parasite. Secondary mucosal folds were destroyed throughout the entire intestine and primary folds were severly eroded in areas. Spores and trophozoites were numerous, as were inflammatory and red blood cells. 
Examination of the contents of the gall bladder has been suggested in diagnosis of an infection (Amos, 1985). Johnson (1975) noted that infection of the gall bladder occurred late in the infectious process and in this study little or no infection of that organ was observed. When the gall bladder and spleen were infected, trophozoites appeared to have entered from the body cavity. Because the posterior intestine is the primary site of infection and because infection of this tissue always preceeds invasion of other areas, and is more severe than infections in other tissues, we believe examination of the intestine is sufficient for diagnosis of the disease.

The progress of infection in resistant strains of fish was difficult to determine because only two fish of the resistant, North Santiam strain became infected. No evidence of the parasite or any inflammatory response was observed in uninfected, North Santiam steelhead. The appearance of the infection in one of the two fish was similar to that in susceptible fish, indicating that the primary site of infection is the same and once the parasite has penetrated the intestine, the infection proceeds as in susceptible fish. Detection of a trophozoite in the lumen of the intestine of the second fish supports the hypothesis that resistance is at the site of entry. If resistance was due to a cellular or humoral response it would be expected that parasites would be in the tissue. One individual from a susceptible strain also appeared refractory to infection. Many trophozoites were detected in the lumen of its intestine, several were attached to the epithelial surface, and some were present 
between epithelial cells. Although this fish may have eventually succumbed to the infection, it provided additional evidence that the parasite first enters the fish from the lumen of the descending intestine and that exclusion of the parasite from entering at this site may be the mechanism of resistance.

The progress of the infection is temperature dependent, with mean time to death inversely correlated to temperature (Udey et a1.,1975). The histopathology of the infection paralleled this; trophozoites were detected at an earlier time and the inflammatory response developed earlier as temperature increased. Although trophozoites multiplied faster, the progression of events was similar to that in fish held at lower temperatures. These observations are contrary to those of Lom (1969) and Dykova and Lom (1978) who noted a regression of infection by Henneguya species as temperatures increased. It was suggested that antibodies become active at higher temperatures and help destroy the parasite.

No immune response was detected in rainbow trout naturally infected with C. shasta by either Western blotting or IFAT, even though the fish had harbored the parasite for over thirty days and were dying from the infection. This supports the work of other researchers (Siau, 1980; Halliday, 1974; Pauley, 1974) who were unable to detect antibodies against myxosporeans by complement fixation, gel precipitation, or immunoelectrophoresis. One criticism of these studies is that they were trying to detect antibodies against the spore stage of the parasite. Spores form later in the infectious process, and spore antigens may differ from those of trophozoites 
(Bartholomew et al., submitted). Therefore, fish antibodies against these early stages may go undetected. Griffin and Davis (1978) were able to demonstrate antibodies against $\mathbf{M}$. cerebralis in naturally infected trout by IFAT; however, their results did not show absolute correlation between the presence of spores and the presence of antibody, and their results required some interpretation because of background fluoresence. Also, results of monoclonal antibody studies (Bartholomew et al., submitted) indicate that $C$. shasta trophozoites and trout immunoglobulin have cross-reacting carbohydrate epitopes. If this is true for other myxosporeans, polyclonal antibodies against trout immunoglobulin may be reacting against the parasite itself rather than against antibody on its surface. It appears that if an immune response is directed against C. Shasta, it is ineffective in halting the infection. Infection by C. shasta fits the description by Plehn (1932) of a super-infection in which invasion leads to a generalized myxosporidiasis and subsequently to death. 


\section{ACKNOWLEDGEMENTS}

We thank Elizabeth MacConnell and Oliva Nunez for their assistance in sectioning fish for the histological study and $\mathrm{Al}$ Soeldner for preparation of samples for the scanning electron microscope. This research was supported by Bonneville Power Administration under contract No. DE-A179-83 BP 11987; G. R. Bouck, Contracting Officer's Technical Representative. Oregon Agricultural Experiment Station Technical Paper No. 8731 


\section{LITERATURE CITED}

Amandi, A, and J. L. Fryer. 1985. Observations on Myxobolus insidiosus (Myxozoa: Myxosporea) a parasite of salmonid fishes. Fish Path. 20:287-304.

Amos, K. H., ed. 1985. Procedures for the detection and identification of certain fish pathogens, 3rd ed. Fish Health Sec., Amer. Fish. Soc., Corvallis, OR.

Bartholomew, J. L., J. S. Rohovec, and J. L. Fryer. Development, characterization, and use of monoclonal and polyclonal antibodies against the myxosporean, Ceratomyxa shasta. (manuscript submitted).

Buchanan, D. V. , J. E. Sanders, J..L. Zinn, and J.L. Fryer. 1983. Relative susceptibility of four strains of summer steelhead to infection by Ceratomyxa shasta. Trans. Amer. Fish. Soc. 112:541-543.

Ching, H. L., and D. R.. Munday. 1984. Susceptibility of six Fraser chinook. salmon stocks to Ceratomyxa shasta and the effects of salinity on ceratomyxosis. Can. J. Z001. 62:1081-1083.

Cohen, A. L., D. P. Marlow, and G. E. Garner. 1968. A rapid critical point method using fluorocarbons (Freons) as intermediate and transitional fluids. J. Micr. 7-3:33 1-342.

Conrad, J. F., and M. Decew. 1966. First report of Ceratomyxa in juvenile salmonids in Oregon. Prog. Fish-Cult. 28:238.

Duhamel, G. E., M. L. Kent, N. 0. Dybdal, and R. P. Hedrick. 1986.

Henneguya exilis Kudo associated with granulomatous branchitis of channel catfish Ictalurus punctatus (Rafinesque). Vet. Path. 23:354-361.

Dykova, I., and J. Lom 1978. Histopathological changes in fish gills infected with myxosporidian parasites of the genus

Henneguya. J. Fish Biol. 12:197-202. 
Fantham, H., and A. Porter. 1.912. Some effects of the occurrence of myxosporidia in the gall bladder of fishes. Ann. Trop. Med. Parasitol. 6:467-48 1.

Griffin, B., and E. Davis. 1978. Myxosoma cerebralis: Detection of circulating antibodies in infected rainbow trout (Salmo gairdneri). J. Fish. Res. Board Can. 35:1186-1 190.

Halliday, M. 1974. Studies on Myxosoma cerebralis, a parasite of salmonids. IV. A preliminary immunofluorescen $t$ investigation of the spores of Myxosoma cerebralis. Nordic Vet. Med. 26: 173-179.

Halliday, M. 1976. The biology of Myxosoma cerebralis: The causative organism of whirling disease of salmonids. J. Fish Biol. 9:339-357.

Hoffmaster, J. L., J. E. Sanders, J. S. Rohovec, J. L. Fryer, and D. G. Stevens. 1988. Geographic distribution of the myxosporean parasite, Ceratomyxa shasta Noble, 1950, in the Columbia River basin, USA. J. Fish Dis. 11:97-100.

Jakowska, S., and R. Nigrelli. 1953. The pathology of myxosporidiosis in the electric eel, Electrophorus electricus (Linnaeus), caused by $\mathbf{H e n n e g u y a ~ v i s c e r a l i s ~ a n d ~} \mathbf{H}$. electrica spp. nov. Zool. 38:183-191.

Johnson, K. A. 1975. Host susceptibility, histopathologic, and transmission studies on Ceratomyxa shasta, a myxosporidan parasite of salmonid fish. $\mathrm{PhD}$ Thesis, Oregon State Univ., Corvallis OR. 134 p.

Kent, M. L., and R. P. Hedrick. 1985. PKX, the causative agent of proliferative kidney disease (PKD) in Pacific salmonid fishes and its affinities with the Myxozoa. J. Protozool. 32:254-260.

Lom, J. 1969. Cold-blooded immunity to protozoa. In: Immunity to Parasitic Animals. Vol. 1 (ed. by G. J. Jackson, R, Herman, and I. Singer), p. 249-265. Appleton-Century-Crofts, New York. 
Lom, J. 1970. Protoza causing diseases in marine fishes. In: A Symposium of Fishes and Shellfishes (ed. by S. Snieszko), p. 101-123. Amer. Fish. Soc. Spec. Publ. No. 5. Washington, D. C.

Margolis, L., and T. P. Evelyn. 1975. Ceratomyxa shasta (Myxosporida) in chum salmon (O ncorhynchus keta) in British Columbia. J. Fish. Res. Board Can. 32:1640-1643.

Noble, E. 1941. Nuclear cycles in the life history of the protozoan genus Ceratomyxa. J. Morph.. 69:455-479.

Noble, E. R. 1944. Life cycles in the Myxosporidia. Quart. Rev. Biol. 19:213-235.

Noble, E. R. 1950. On a myxosporidian (protozoan) parasite of California trout. J. Parasitol. 36:457-460.

Pauley, G. 1974. Fish sporozoa: Extraction of antigens from Myxosoma cerebralis which mimic tissue antigens of rainbow trout (Salmo gairdneri, Rafinesque). J. Fish. Res. Board Can. 31:1481-1484.

Plehn, M. 1932. Eine Schleienbrut-Krankfeit und ihr Erreger, Sphaerospora tincae n. sp. Inter. Rev. Ges. Hydrobiol. Hydrograph. 26:265-280.

Roberts, R. J., and K. G. R. Elson 1970. An outbreak of whirling disease in rainbow trout. Vet. Rec. 86:258-259.

Schafer, W. E. 1968. Studies on the epizootiology of the myxosporidian Ceratomyxa shasta Noble. Calif. Fish Game. 54:90-99.

Siau. Y. 1980. Immunologic observations in fishes of the genus Mugil parasitized by the myxosporidan Myxobolus exiguus Thelohan, 1895. Zeitschrift Parasitenkd. 62: 1-6.

Taylor, R. E., and M. H. Haber 1974. Opercular cyst formation in trout infected with Myxosoma cerebralis. J. Wildl. Dis. 10:347-35 1. 
Udey, L. R., J. L. Fryer, and K. S. Pilcher. 1975. Relation of water temperature to ceratomyxosis in rainbow trout (Salmo gairdneri) and coho salmon (0 ncorhynchus kisutch). J. Fish. Res. Board Can. 32:1545-1551.

Wales, J. H. and H. Wolf. 1955. Three protozoan diseases of trout in California. Calif. Fish Game. 41:183-187.

Yamamoto, T. and J. E. Sanders. 1979. Light and electron microscopic observations of sporogenesis in the myxosporidan, Ceratomyxa shasta (Noble, 1950). J. Fish Dis. 2:41 1-428.

Zinn, J. L., K. A. Johnson, J. E. Sanders, and J. L. Fryer. 1977. Susceptibility of salmonid species and hatchery strains of chinook salmon (O ncorhynchus tshawytscha) to infections by Ceratomyxa shasta. J. Fish. Res. Board Can. 34:933-936. 
CHAPTER III

\title{
CHARACTERIZATION OF A MONOCLONAL ANTIBODY AGAINST
} CERATOMYXA SHASTA USING IMMUNOCYTOCHEMISTRY

J. L. Bartholomewl, T. Yamamoto ${ }^{2}$, J. S. Rohovecl, and J. L. Fryer ${ }^{1}$

\author{
1 Department of Microbiology \\ Oregon State University \\ Corvallis, Oregon 97331 \\ 2Department of Microbiology \\ University of Alberta \\ Edmonton, Alberta, Canada T6G 2E9
}




\begin{abstract}
The antigenic specificity of a monoclonal antibody (Mab) against Ceratomyxa shasta was investigated using immunogold labeling techniques and transmission electron microscopy and by immunoenzymatic labeling. Specific binding by the Mab was observed in the cytoplasm of the primary cell. Label was not observed in the cytoplasm of the developing secondary cells or in the nucleus of either the primary or secondary cells. A hypothesis explaining the specificity of this Mab for prespore stages of the parasite is presented.
\end{abstract}




\section{INTRODUCTION}

A monoclonal antibody (Mab) specific for the myxosporean salmonid parasite, Ceratomyxa shasta, has been developed and characterized (Bartholomew et al., submitted). This Mab reacts specifically with the trophozoite and sporoblast stages of the parasite in indirect fluorescent antibody tests (IFAT). In Western blot analysis it recognizes many polypeptide bands from these prespore stages, suggesting that it is formed against a common epitope. The Mab did not react with C. shasta spores by immunoblotting procedures, Western blot analysis, or IFAT. These data indicate that the parasite has stage-specific antigens and that Mabs may not react against all life stages.

Antibodies that recognize early life stages of C. shasta would be helpful in studying the biology and life cycle of the parasite. Presently, the only life stages identified are those that exist within the salmonid host. A Mab recognizing trophozoites may also recognize stages of the parasite prior to infection of the fish and could be used to look for these stages in water and invertebrates collected from endemic sites. In this study the specificity of the Mab was investigated by using immunogold electron microscopic techniques and immunoenzymatic labeling of histological sections. 
MATERIALS AND METHODS

\section{Immunogold Electron Microscopy}

To determine the location of the antigens against which the monoclonal antibodies are directed immunogold labeling procedures were used. Prespore stages of the parasite from the ascites of infected rainbow trout were fixed for $1 \mathrm{~h}$ in $2.5 \%$ glutaraldehyde in $0.1 \mathrm{M}$ phosphate buffered saline, $\mathrm{pH} 7.6$ (PBS). The suspension was centrifuged to pellet the cells which were resuspended in PBS. Cells were embedded in Spurr's resin (Spurr, 1969) without $\mathrm{OsO}_{4}$ staining. Sections were cut on an ultramicrotome and mounted on nickel grids. The embedding medium was etched with sodium metaperiodate (saturated solution in distilled water) for $30 \mathrm{~min}$, washed with distilled water, then blocked with $100 \mathrm{mM}$ glycine $+5 \%$ bovine serum albumin in PBS for $15 \mathrm{~min}$. Sections were incubated with undiluted monoclonal antibody for $1 \mathrm{~h}$ at room temperature. After washing three times with PBS, grids were incubated with biotinylated anti-mouse IgG (1: 100 in PBS)(Hyclone Laboratories, Logan, Utah) for $1 \mathrm{~h}$, washed, and incubated for $30 \mathrm{~min}$ with Streptavidin-gold (1:200 in PBS)(particle size, $20 \mathrm{~nm})($ Polysciences Inc., Warrington, PA). In control experiments, the incubation conditions were identical except that non-immune serum or PBS was substituted for specific antibody in the first incubation step. All grids were washed thoroughly, first with PBS then with distilled water, and examined with a Philips EM-301 transmission electron microscope. Some 
grids were post-stained with $2 \% \mathrm{OsO}_{4}(5 \mathrm{~min})$, uranyl acetate (2 $\min )$ and lead citrate $(5 \mathrm{~min})$.

\section{Immunoenzymatic Staining}

For examination of the parasite in tissue sections, viscera of fish exposed to the infectious stage of C. shasta were fixed in $10 \%$ neutral buffered formalin, processed routinely for histology to 6 $\mu \mathrm{m}$, and mounted on gelatin coated slides. Sections were dewaxed and hydrated in 2 changes each of xylol, absolute ethanol, 95\% ethanol, and were transferred to water. Sections were incubated with undiluted anti-C. shasta monoclonal antibody for $1 \mathrm{l} / 2$ to $3 \mathrm{~h}$ at room temperature then rinsed with PBS. Sections were then incubated with biotinylated goat anti-mouse Ig streptAvidinperoxidase conjugate (Biogenex, Dublin, CA). The enzymatic activity was localized with the substrate hydrogen peroxide-AECacetate buffer (Biogenex, Dublin, CA). Sections were counterstained with a non-alcoholic solution of hematoxylin (Meyer's) to provide a contrasting background stain. 


\section{RESULTS AND DISCUSSION}

Specific binding by the Mab was observed by electron microscopy to occur in the cytoplasm of the prespore stages of $\mathrm{C}$. Shasta. Gold particles were randomly distributed in the cytoplasm and on the cell membrane of the primary (mother) cell but did not appear to bind to any specific organelle. Label was not observed in the cytoplasm of the developing secondary (daughter) cells or in the nucleus of either the primary or secondary cells. No gold binding occurred in prespore stages incubated with either normal mouse serum or PBS which served as negative controls (Fig. III. 13). Immunoenzymatic staining of trophozoites in histological sections also showed that the antibody binding sites were on the surface and in the cytoplasm of the primary cell (Fig. 111.4). Secondary cells were clearly outlined and were not stained. Chromogen was also observed outside the trophozoite, suggesting that the antigen may be secreted.

Association of the gold particles with the cytoplasm of the primary cell may explain why this Mab recognizes only prespore stages of C. shasta and not mature spores. The first recognizable stages of the parasite in the fish are unicellular. This cell undergoes nucleogomy, the process of forming a multinuclear cell from a uninuclear cell, and eventually consists of a primary cell enveloping two sporoblasts. Each sporoblast contains two sporogenic, two capsulogenic, and two gametogenic cells (Noble, 1941; Yamamoto and Sanders, 1979). The primary cell is present 
until mature spores are released; therefore, antigens present only in the cytoplasm of this enveloping cell may not be present in the mature spore.

Observation of the antigen recognized by this Mab gives additional support for its usefulness as a diagnostic reagent for prespore stages of C. Shasta. The location of the antigen in the cytoplasm of the early stages offers some hope that this antigen would be present in life stages that exist outside of the salmonid. 
Figure III. 1. Transmission electron micrograph of a Ceratomyxa shasta trophozoite incubated with normal mouse serum and immunogold reagents. 5700x.

Figure 111.2. Ceratomyxa shasta trophozoite incubated with monoclonal antibody and immunogold reagents. Arrows indicate gold label on cell surface and in the cytoplasm. $7100 x$.

Figure 111.3. Ceratomyxa shasta trophozoite incubated with monoclonal antibody and immunogold reagents. Gold label diffusely scattered in primary cell cytoplasm. Unstained, 11000X. 


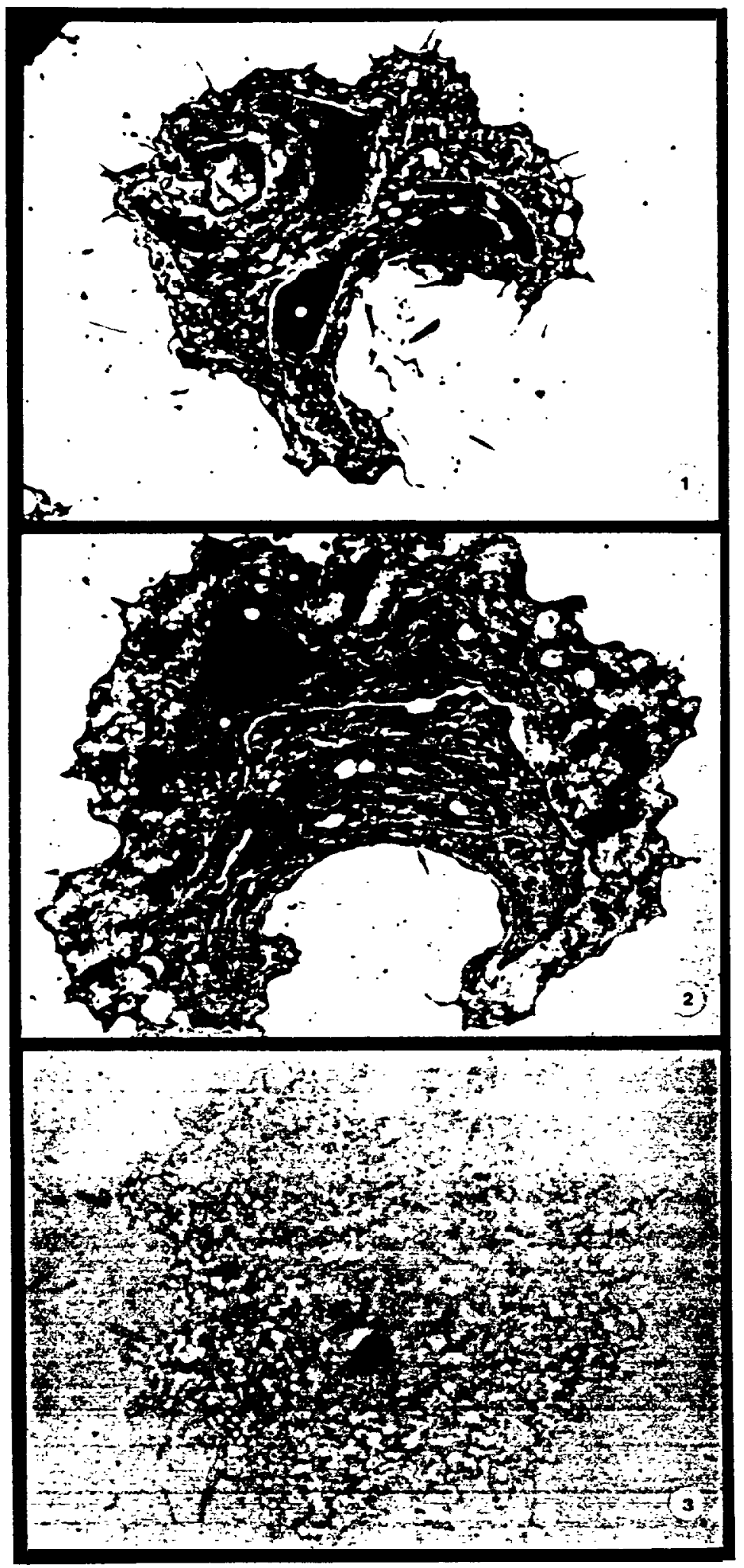


Figure 111.4. Immunoenzymatic stain of Ceratomyxa shasta trophozoites in a histological section. Chromogen stains only the cytoplasm of the primary cell, secondary cells are unlabeled. x1000 


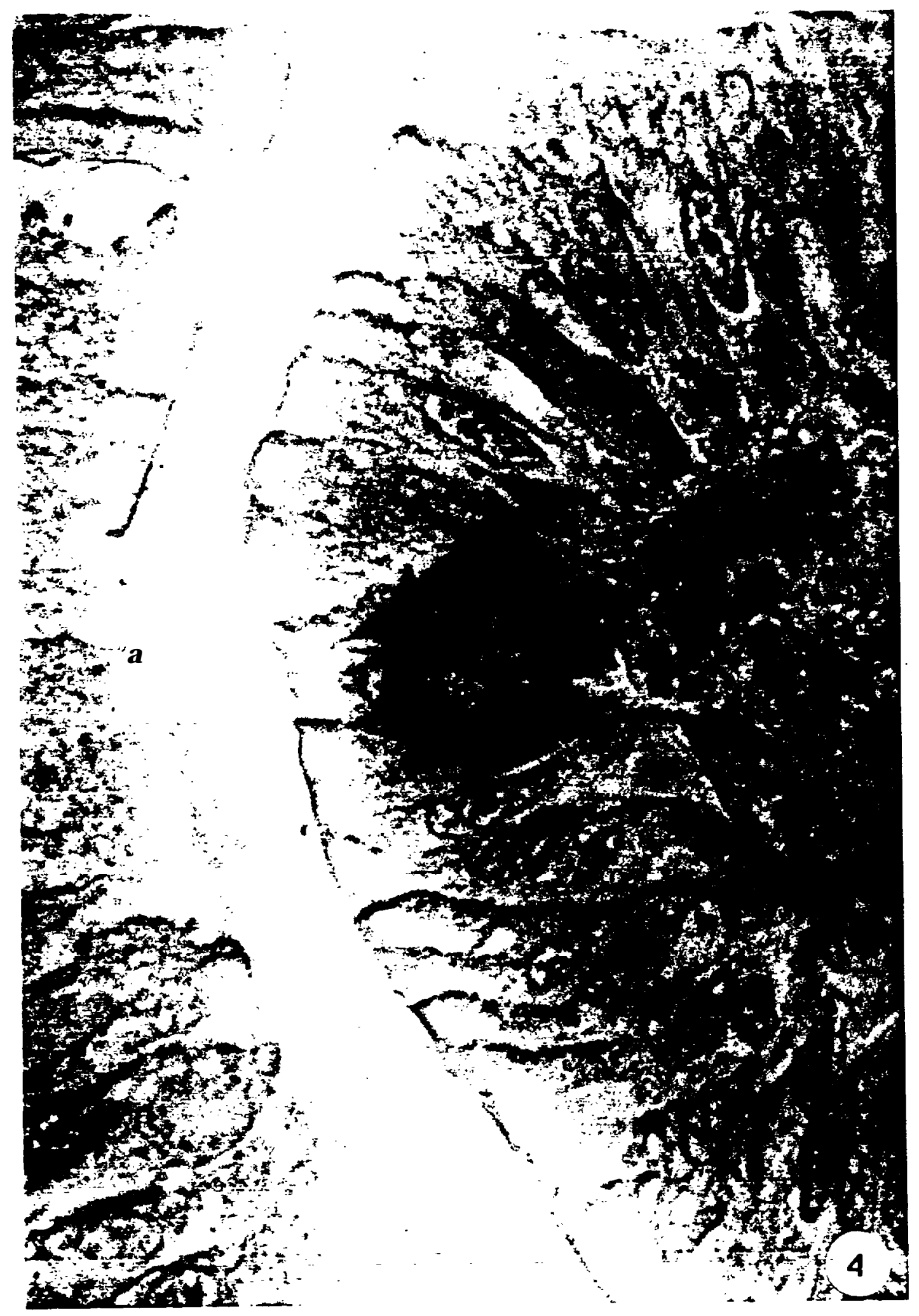




\section{ACKNOWLEDGEMENTS.}

The authors wish to thank Jim Winton for arranging use of the facilities used in this study and Cindy Arakawa for her assistance. This research was supported by Bonneville Power Administration under contract No. DE-Al79433 BP 11987; G. R.

Bouck, Contracting Officer's Technical Representative. Oregon Agricultural Experiment Station Technical Paper No. 8732. 


\section{LITERATURE CITED}

Bartholomew. J. L., J. S. Rohovec, and J. L. Fryer. Development, characterization, and use of monoclonal and polyclonal antibodies against the myxosporean, Ceratomyxa shasta. (manuscript submitted)

Noble, E. 1941. Nuclear cycles in the life history of the protozoan genus Ceratomyxa. J. Morph. 69:455-479.

Spurr, A. R. 1969. A low viscosity epoxy resin embedding medium for electron microscopy. J. Ultrastr. Res.. 26:31-34.

Yamamoto, T., and J. E. Sanders. 1979. Light and electron microscopic observations of sporogenesis in the myxosporida, Ceratomyxa shasta (Noble, 1950). J. Fish Dis. 2:411-428. 


\title{
CHAPTERIV
}

\section{ARTIFICIAL TRANSMISSION OF CERATOM YXA SHASTA VIA POTENTIAL INTERMEDIATES}

D. G. Stevens, J. L. Bartholomew, J. S. Rohovec and J. L. Fryer

\author{
Department of Microbiology \\ Oregon State University \\ Corvallis, Oregon 97331, USA
}




\begin{abstract}
The life history of Ceratomyxa Shasta, a myxosporean parasite of salmonid fish, is unknown. Transmission occurs naturally when susceptible fish are exposed to waters containing the infectious unit which remains undescribed. The inability to obtain transmission from infected fish to susceptible animals and the geographic limits within a river of the infectious zone suggest the involvement of an intermediate host in the life cycle. Preliminary laboratory experiments with the freshwater mussel (Margaritifera margaritifera) have resulted in transmission. We have examined several parameters necessary for reproducible transmission to occur under laboratory conditions. Although the exact role of the mussel has not been determined, experiments indicate a low number of the animals are involved.
\end{abstract}




\section{INTRODUCTION}

Artificial transmission and description of the complete life history of only one Myxosporean parasite has been accomplished (Wolf and Markiw, 1984). The causative agent of whirling disease, Myxobolus (Myxosoma) cerebralis, develops from trophozoites to adult spores in the cartilage of juvenile salmonids. When the spores are released they apparently develop into triactinomyxons within the oligochaete worm Tubifex tubifex. The triactinomyxons then complete the life cycle by infecting young fish. Although many other Myxosporeans are parasites of fish, the life history of none other than $\mathbf{M}$. cerebralis has been described.

Unlike M. cerebralis, Ceratomyxa Shasta has a limited geographic range and that range is unique because only certain areas of the range where diseased fish are found have conditions which allow infections to occur (Bartholomew et al. (in press), Johnson et al., 1979). The geographic range in which infections can be initiated include the Willamette River up to river mile 134 (near Corvallis, Oregon). Conditions that are necessary for the transmission of $\mathbf{C}$. shasta have not been described and therefore the life history of this organism remains an enigma.

Preliminary studies to determine if aquatic invertebrates are required in some stage of the life cycle of C. shasta have been performed (Fryer, 1988). It was noted that fresh water mussels collected from a site where fish can be infected were involved in the transmission of C. Shasta. Although experiments have been 
repeated, the results are not consistantly reproducible. The parameters necessary for C. shasta infections to occur were investigated. 


\section{MATERIALS AND METHODS}

\section{Experimental Animals}

Rainbow trout susceptible to C. shasta were obtained from Oak Springs Hatchery and the OSU Food Toxicology and Nutrition Laboratory. The fish were held at the OSU Fish Disease Laboratory and Western Fish Toxicology Laboratory, United States Environmental Protection Agency Laboratory in Corvallis, Oregon. To infect fish with C. shasta, fish were held in live boxes in the Willamette River near Corvallis (Udey et al., 1975). Fish were fed Oregon Biodiet with 4\% TM-50.

Invertebrate animals were collected by hand or dredged from the Willamette River at mile 129.6 or 121.4. Invertebrate groups studied included Oligochaete worms (Kincaidiana hexatheca), clams (Corbicula fluminea), and freshwater mussels (Margaritifera margaritifera). Freshwater mussels were also collected from the Siletz River near Siletz, Oregon, a site where C. shasta is not endemic. The mussels and clams were fed a mixture of 3 parts instant yeast to 1 part brown rice flour.

Laboratory exposures were conducted in 1 and 20 gallon tanks supplied with well water at a constant 15 C. Fish were finclipped to differentiate among different groups. 


\section{Continued exposure of trout and Siletz River mussels to C. shasta}

Susceptible rainbow trout and infected fish or viscera and ascites fluid collected from infected trout were added to tanks containing Siletz River mussels which had been collected six months earlier. More than half of the mussels remained alive and this second exposure was similar to the first where susceptible fish were exposed to infected fish or viscera and ascites fluid with and without mussels present. Five susceptible trout were added to each of five aquaria containing five mussels. Three aquaria were supplied with infected fish, one with viscera and ascites fluid, and one served as a laboratory water control. Fish were kept in contact with the mussels for 14 weeks and monitored for infection by $\mathrm{C}$. shasta. Following this exposure, the mussels and an additional lot of susceptible fish were placed in the effluent from a tank of fish which had been infected in the river and were dying from C. shasta. The fish were exposed for four weeks.

\section{Transmission of C. shasta using various substrates with rinsed and brushed mussels}

Mussels collected from river beds live in close association with Oligochaete worms and generally have a significant algal growth on the portion of the valves exposed to the river. Therefore, tests are conducted with and without this algal covering to determine if it is involved in transmission. Duplicate tanks were 
prepared with the following substrates: 1) dirt, sand, and rock with rinsed mussels; 2) dirt, sand, and rock with brushed mussels; 3) sand with rinsed mussels; 4) sand with brushed mussels; 5) glass beads with brushed mussels: 6) rinsed mussels with no substrate. Control tanks included horizontal (fish to fish) transmission, and laboratory water. Five susceptible uninfected and infected fish were added to different experimental tanks immediately or after the contents had been held overnight with aeration followed by three days of water flow. Fish which died were removed, examined, and returned to the tank to decay naturally. Replacement fish were added to the tank where infections occurred at days 39 and 54 of the test.

After the last replacement fish were exposed for seven days, they were removed and placed in clean water for observation. The mussels were removed from the large tank and placed in individual small aquaria with three susceptible trout. This exposure was continued for three months. Fish that died were examined for C. shasta infections and replaced with naive fish. Six days after initiation of the test, water samples were collected and stored for examination pending the appearance of infections.

Examination of the possible role of Oligochaete worms in the transmission of $\mathrm{C}$. shasta

Previous preliminary experiments in this laboratory did not show that Oligochaetes are involved in the transmission of C. Shasta. 
We designed further tests to examine the role of worms in the life cycle of C. Shasta. Four tanks were prepared with a substrate of sterilized soil and sand. These tanks were supplied with worms (Kincadiana hexatheca) only, worms and mussels, mussels only, both brushed and rinsed. Controls for horizontal transmission and laboratory water were included. Fifty worms and ten mussels were added to the appropriate tanks with five infected and an equal number of susceptible fish.

\section{Effect of increased temperature on the release of infectious units from mussels removed from the river during the winter}

Experiments conducted, previously indicated that mussels removed from the river during February were capable of infecting susceptible fish with C. shasta for a period of at least 30 days. A similar experiment was conducted, however, the susceptible fish were removed after various exposure times. Mussels were hand collected in February, brushed, and placed in a tank in which water temperature could be controlled. The river temperature was $8 \mathrm{C}$ at the time of collection and the temperature of the laboratory tank set at $10 \mathrm{C}$ to match that of the transport water upon arrival at the laboratory. Susceptible rainbow trout were added immediately and the temperature was raised to $12.5 \mathrm{C}$ at a rate of $0.7 \mathrm{C}$ per day. Separate lots of fish were exposed to the mussels for different time intervals: two groups for periods of seven days, one for a period of two weeks, and a fourth group for 30 days. Each group was kept in 
clean water for a minimum of 42 days prior to examination for $\mathrm{C}$. shasta infections.

\section{Exposure of rainbow trout to mussels and mussel pallial fluid}

Exposures of fish to mussels and mussel pallial fluid were conducted to evaluate the handling procedures and how they may affect our ability to obtain transmission. Collecting pallial fluid from the mussel immediately after removal from the river might indicate if viable infectious units were present but were being killed or diluted in the handling process.

Forty mussels were dredged from the river, blotted dry, and the pallial fluid collected. Another group of mussels was collected and handled similarly but without taking the pallial fluid. Both groups were brushed and placed in clean well water for transport to the laboratory. Susceptible fish were exposed to the pallial fluid, the transport water, and to the effluent from four tanks containing twenty mussels each. One liter water samples were collected on day one and day two of the test. These were to be examined, if infections occurred, for the presence of infectious unit using monoclonal antibodies and IFAT. 


\section{Exposure of rainbow trout to mussels and clams from the Willamette River near Albany}

River exposures of susceptible fish have not always been consistant in the Corvallis area (Johnson, 1975) and because experiments conducted earlier this year with mussels collected near Corvallis produced similar inconsistant infections, it was decided to collect mussels further downstream where the concentration of infectious units might be greater.

Mussels and clams were collected from a location, near the city of Albany, eight miles downstream (river mile 121.4) from the original sampling area. The mussels and clams were washed and rinsed before placement in tanks with either sand or sand and mud. Two tanks with 20 mussels and two tanks with 20 mussels and 50 clams were stocked with either ten susceptible or ten susceptible and 5 infected fish. The fish were added to the tanks after overnight aeration without water flow followed by three days of water flow. Dead fish were removed for examination and those positive for C. shasta were cut open and returned to the tank. The fish were exposed for a minimum of eight weeks. Following the initial exposure replacement fish were added to two of the tanks and experiments in two tanks were terminated. If infections continue to occur the mussels will be sacrificed and prepared for histological examination. 


\title{
RESULTS AND DISCUSSION
}

\section{Continued exposure of trout and Siletz River mussels to C. shasta}

\author{
None of the fish exposed to Siletz River mussels and C. shasta \\ organisms became infected. Only one fish died during the 14 week \\ exposure and it was not infected. Likewise, exposure to the effluent \\ from the tank of infected fish produced no infections. After more \\ than a year of intermittent exposure to infected fish and infected \\ viscera, no infections have occurred from the association of \\ susceptible rainbow trout with the mussels from the Siletz River, a \\ non-infectious stream. If the mussels from infectious areas are \\ truly associated with transmission of the disease, the requirements \\ necessary to initiate their involvement have not been met by the \\ conditions of these tests.
}

\section{Transmission of C. shasta using various substrates with rinsed and brushed mussels}

Because we have been unable to produce consistant infections, susceptible fish were introduced at selected intervals to tanks containing three different substrates and different mussel preparations to determine conditions necessary for transmission of C. Shasta. Infections occurred in one tank only in which there were mussels on a substrate of glass beads (Table 1). All of these fish 
Table 1. Exposure of rainbow trout to the mussels (M. margaritifera) collected from a site infectious for Ceratomyxa shasta and held on selected substrates.

\begin{tabular}{|c|c|c|c|}
\hline \multirow{2}{*}{$\begin{array}{l}\text { Substrate type } \\
\text { Mud, sand, rock }\end{array}$} & \multirow{2}{*}{$\begin{array}{c}\text { Mussel } \\
\text { Treatment } \\
\text { Rinsed }\end{array}$} & \multicolumn{2}{|c|}{ Fish Introductiona } \\
\hline & & $0 / 5^{c}$ & $0 / 5$ \\
\hline Sand & Rinsed & $0 / 5$ & $0 / 5$ \\
\hline Mud, sand, rock & Brushed & $0 / 5$ & $0 / 5$ \\
\hline Sand & Brushed & $0 / 5^{d}$ & $0 / 5$ \\
\hline Glass beads & Brushed & & $5 / 5$ \\
\hline Glass beads & & & \\
\hline (first replacement fish) & & $1 / 5^{\mathrm{e}}$ & \\
\hline (second replacement fish) & & $0 / 5$ & \\
\hline No substrate & Rinsed & & $0 / 5$ \\
\hline Fish to fish control & & $0 / 5$ & \\
\hline Laboratory water control & & $0 / 5$ & \\
\hline
\end{tabular}

a Five infected fish were added to all tanks except where noted. bFish were introduced after overnight aeration without water flow followed by 3 days of flow at $1 \mathrm{gpm}$.

$c_{\text {Number infected/number exposed. }}$

dOnly susceptible fish were added to this tank.

e Replacement fish were added to this tank 39 and 54 days after start of test. 
were heavily infected with C. Shasta. Dead fish were examined and those positive for C. shasta were cut open and returned to the tank. Of the new fish added to the tank 39 days after initiation of the test, only one of five became infected. None of the fish in the second replacement group became infected. Placement of individual mussels in small aquaria with susceptible fish failed to produce additional infections.

These results and those of an earlier study (Fryer, 1988) indicate that a complex substrate is not necessary to obtain transmission. Therefore, the infectious unit must either be harbored by the mussel or is released following developmental changes of spores or trophozoites which are ingested. Previous studies (Ratliff, 1983 ; Johnson, 1975) indicate that the infectious unit does not survive longer than ten days in water alone. Our data continue to indicate that not all mussels are involved because although they are collected and transported to the laboratory together, transmission of the disease does not occur in all aquaria to which mussels are introduced.

\section{Examination of the possible role of Oligochaete worms in the transmission of $C$. shasta}

Oligochaete worms (Tubifex) have been tested previously and failed to facilitate transmission of ceratomyxosis. However, the close association of the native species (Kincaidiana hexatheca) with the mussels in the river beds prompted another study. No disease 
transmission occurred in fish held with worms alone or worms in association with mussels. In this experiment no transmission occurred in any of the tanks with mussels. The river water temperature was only $10.5 \mathrm{C}$ when the organisms were collected and fish exposed to the river water only suffered a $50 \%$ loss from C. shasta. These conditions may have been responsible for the lack of laboratory infections.

\section{Effect of increased temperature on the release of infectious units from mussels removed from the river during the winter}

Mussels collected in February when the river temperature was $8 \mathrm{C}$ were gradually warmed to $12.5 \mathrm{C}$, and trout were exposed to the mussels for up to one month. No transmission occurred in the test; however, transmission had occurred in a similar test conducted previously.

\section{Exposure of rainbow trout to mussels and pallial fluid}

No infections were obtained from either the mussels, pallial fluid, or the water used to transport the animals. Prior to initiation of this test, the river was infectious to nearly $50 \%$ of the fish exposed. However, the positive controls from the river, exposed during the first week of the test, only suffered 13\% mortality from C. Shasta. This may have been the result of heavy rains which 
raised the river level and possibly diluted the concentration of $\mathrm{C}$. shasta organisms.

\section{Exposure of rainbow trout to mussels and clams from the Willamette River near Albany}

Mussels and clams were collected from a site near Albany, OR and examined for their involvement in disease transmission. Infections of naive fish were obtained in one tank where infected fish had been added (Table 2). Seven of ten were positive for C. Shasta. Replacement fish were added to the tank in which infections occurred and to date three of the fish have died and were positive for C. Shasta. Water samples were taken from the aquarium and slides are being examined for detection of the infectious unit. In a replicate tank, in which no infections occurred, and additional fish, both infected and naive, were added with viscera and ascites fluid, transmission has failed to occur to this date.

As in previous experiments, infections occurred in only one tank of fish exposed to replicate groups of mussels. This continues to suggest that not all mussels are involved in the transmission of ceratomyxosis. This study is being continued and others are planned to identify the role of the mussel in the transmission of ceratomyxosis. 
Table 2. Exposure of rainbow trout to mussels and clams from the Willamette River near Albany.

Test Organisma Type of Fish

$\begin{array}{cc}\text { Number } & \text { of Fish } \\ \text { Exposed }^{c} & \text { Infected }\end{array}$

10

0

Susceptible and infected ${ }^{b}$

Susceptible

Susceptible and infected
10

10

10
7

0

0

\begin{abstract}
aEach tank contained either 20 mussels or 20 mussels and 50 clams.

bFive fin-clipped infected fish were added where indicated. cStock fish served as laboratory water control. Trout exposed to water where the clams and mussels were collected suffered 100\% mortality from C. Shasta.
\end{abstract}




\section{ACKNOWLEDGEMENTS}

The cooperation of the Environmental Protection Agency Corvallis Environmental Research Laboratory is recognized for providing some of the fish holding facilities at the Western Fish Toxicology Laboratory. The Oregon Department of Fish and Wildlife and the OSU Food Toxicology and Nutrition Laboratory provided experimental fish. This research was supported by the region's electrical rate payers through the Bonneville Power Administration. 


\section{LITERATURE CITED}

Bartholomew, J. L., J. S. Rohovec and J. L .Fryer. 1989. Ceratomyxa Shasta, a Myxosporean parasite of salmonids. U.S. Fish and Wildlife Service Fish Disease Leaflet (in press).

Fryer, J. L. 1988. Epidemiology and control of infectious diseases of salmonids in the Columbia River basin. Annual Report of Project No. 83-312. U.S. Department of Energy, Bonneville Power Administration.

Johnson, K. A. 1975. Host susceptibility, histopathologic, and transmission studies on Ceratomyxa Shasta, a myxosporidan parasite of salmonid fish. Ph.D. Thesis, Oregon State University, Corvallis, OR. 134 p.

Johnson, K. A., J E. Sanders, and J. L. Fryer. 1979. Ceratomyxa shasta in salmonids. U.S. Fish and Wildlife Service Fish Disease Leaflet 58. 11 p.

Ratliff, D. E. 1983. Ceratomyxa Shasta: longevity, distribution, timing, and abundance of the infective stage in central Oregon. Canadian Journal of Fisheries and Aquatic Sciences. 40: $1622-1632$.

Udey, L. R., J. L. Fryer, and K. S. Pilcher. 1975. Relation of water temperature to ceratomyxosis in rainbow trout (Salmo gairdneri) and coho salmon (0 ncorhynchus kisutch). Journal of the Fisheries Research Board of Canada. 32:1545-1551.

Wolf, K. and M. E. Markiw. 1984. Biology contravenes taxonomy in the Myxozoa: new discoveries show alternation of invertebrate and vertebrate hosts. Science. 255:1449-1452. 


\title{
CHAPTER V
}

\section{IN VITRO INHIBITION OF RENIBACTERIUM SALMONINARUM BY EXPERIMENTAL ANTIBIOTICS.}

S.K. Gutenberger, O.B. Dale, and J.S. Rohovec

\author{
Department of Microbiology \\ Oregon State University \\ Corvallis, Oregon USA
}




\begin{abstract}
Over one hundred experimental antibiotics were incorporated into KDM-2 agar and tested on four strains of $\mathbf{R}$ enibacterium salmoninarum. R. salmoninarum was susceptible to 51 of the compounds, with 19 of these effectively inhibiting at $1 \mathrm{mg} / \mathrm{L}$ or less. Four other fish pathogens, Streptococcus sp., Aeromonas salmonicida, Edwardsiella tarda, and Cytophaga psychrophila, were also tested. Streptococcus was inhibited by 42 of the antibiotics, 33 of which also inhibited R. salmoninarum. Four antibiotics inhibited all bac teria tested. Two drugs were effective against all bacteria except R. salmoninarum. Seventeen of the drugs inhibited only $\mathbf{R}$. salmoninarum, Streptococcus, and C. psychrophila. A total of 32 of the experimental compounds had no inhibitory effect on any of the bacteria.

A microtiter plate assay for testing antimicrobial compounds was developed for $\mathbf{R}$. salmoninarum and compared to the agar plate method. The results from the microtiter plate assay were comparable to, and in some cases more sensitive than the agar plate assay. The microtiter plate assay was more cost effective, saving both time and media.
\end{abstract}




\section{INTRODUCTION}

Renibacterium salmoninarum, the causative agent of bacterial kidney disease (BKD) is one of the most devastating bacterial diseases of salmonid fish (Fryer and Sanders, 1981). The organism is unique among bacteria. It is a very slow-growing organism which has an absolute nutritional requirement for cysteine. The bacterium causes a systemic infection which is usually chronic. Currently there are no effective vaccines against BKD (Kaattari et al, 1988). The disease is difficult to treat, probably because of the ability of the organism to survive phagocytosis by macrophages. Currently, erythromycin is the drug of choice for therapy, but treatments are not always successful. Others (Wolf and Dunbar, 1959; Austin, 1985) have evaluated antimicrobial compounds for control of BKD and of the drugs that were tested, erythromycin was the most effective. Unfortunately, this antibiotic is not yet approved for use in food fish and laboratory studies have shown that $\mathbf{R}$. salmoninarum can become resistant to the effects of the drugs (Bell et al, 1988). We initiated this study to test new antimicrobial compounds for their in vitro effectiveness against $\mathbf{R}$. salmoninarum. 


\section{METHODS AND MATERIALS}

Bacterial Strains: Four isolates of Renibacterium salmoninarum (type strains ATCC 33209 and 33739; D-6, an USA isolate from coho salmon (O ncorhynchus kisutch); and 932, a Norwegian isolate from Atlantic salmon (Salmo salar)) were grown for 5-8 days in KDM-2 broth with $10 \%$ equine serum at $16^{\circ} \mathrm{C}$, to an O.D.520 between 0.7 1.1. Prior to use, the purity of the cultures was verified by ApiZym enzyme test strips (API, Plainville, New York) and by Gram stain.

Four other fish pathogens were also tested, including the gram-negative bacteria Aeromonas salmonicida, Cytophaga psychrophila and Edwardsiella tarda. Streptococcus sp., a grampositive bacterium, was added as control for the R. salmoninarum. A. Salmonicida, E. tarda and Streptococcus were grown in tryptone soy broth and C. psychrophila was grown in typtone yeast extract at $16^{\circ} \mathrm{C}$ for $24-48$ hours. All bacterial cultures had greater than 107 colony forming units/ml (cfu) for antibiotic testing. Before actual testing on the antibiotic-incorporated KDM-2 agar, the cfu for each bacterium was compared on plates of KDM-2 and TYE agar. There were no differences in growth on either media for A. salmonicida, E. tarda and Streptococcus. Growth on KDM-2 agar by C psychrophila was reduced $(6.2 \mathrm{X} 106 \mathrm{cfu} / \mathrm{ml})$ in comparison to that on TYE agar $(2.1 \mathrm{X} 107 \mathrm{cfu} / \mathrm{ml})$ but was more than adequate for antibiotic testing. 
Preparation of Antibiotics: Over 100 antibiotics, untested on fish pathogens, were obtained from Eli Lilly \& Co. (104), Merck \& Co. (3), Abbot (1) and Pfizer (1) (Table 1). Thirty-two were derivatives of the macrolide antibiotics erythromycin and tylosin. Another 73 were fermentation products or derivatives. In addition, a fluoroquinolone and a new drug related to penicillin/cephalosporin were included. Immediately before addition to agar, the drugs were weighed and diluted to $1 \mathrm{mg} / \mathrm{ml}$ in either nanopure water, reagent grade methanol, or DMSO:methanol. Those solubilized in water, methanol or methanol: DMSO (4\% DMSO) were filtered through 0.2 um polysulfone acrodisc filters (Gelman, Ann Arbor, MI) into sterile vials. Those drugs solubilized in DMSO:methanol (>4\% DMSO) were not sterile-filtered; however, there were no problems with contamination. Ampicillin (Sigma, St. Louis, MO), rifampicin (Sigma, St. Louis, MO), penicillin-G (Grand Island Biological Co.,Grand Island, NY), erythromycin phosphate (Argent Chemical Laboratories, Inc., Redmond, WA) and oxytetracycline (Sigma, St. Louis, MO) were used as control antibiotics in each of the four trials required to complete the study.

Preparation of Antibiotic Media: Antibiotics were added into sterile $50 \mathrm{ml}$ tubes in amounts to make eight dilutions of each drug: $35,10,5,1,0.5,0.1,0.05$ and $0.01 \mathrm{mg} / \mathrm{L}$. Fifty milliliters of KDM-2 agar (10\% equine serum), $\mathrm{pH}$ 6.8, was added to each tube, mixed, and poured into two $100 \mathrm{~mm}$ quadrant petri dishes. As a positive control for growth and to ensure solvents were not inhibitory to the 
bacteria, each solvent used to solubilize the drugs was incorporated, appropriately diluted, into additional agar plates.

Antibiotic Testing on Agar: Within 24 hours of antibiotic incorporation, $0.1 \mathrm{ml}$ of each bacteria was inoculated into a quadrant. The plates containing $\mathbf{R}$. salmoninarum were sealed with parafilm and all plates were immediately incubated at $160 \mathrm{C}$. The plates of $\mathbf{R}$. salmoninarum were examined at 7,15 and 30 days after inoculation. Those plates inoculated with the other bacteria were examined at 3 and 5 days. For each bacterium, the minimum inhibitory concentration (MIC) was determined to be the lowest concentration of antibiotic that prevented growth.

Antibiotic Testing in Microtiter Plates: For each assay, at least two strains of R salmoninarum (ATCC 33739 and the isolate 932) were used. In one assay, drugs $111,112,113,114$, and 115 were tested with four isolates of R. salmoninarum (ATCC 33209 and 33739, 932 and D-6) and the drug 116 was tested with eight strains (including K-28 from France, 84-019 from open ocean chinook, RC-88 from Oregon, and 325 from Norway). The antibiotics were prepared as described above. To either round or flat-bottomed 96-well microtiter plates (Falcon), KDM-2 broth ( $\mathrm{pH}$ 6.8) with $10 \%$ equine serum was added to wells in amounts to dilute antibiotics to $31.5,10,5,1,0.5,0.1,0.05,0.01$ and $0 \mathrm{mg} / \mathrm{L}$ or, in the last assay, to $25,5,2.5,0.5,0.25,0.05,0.025,0.005,0.0025$, and $0 \mathrm{mg} / \mathrm{L}$. Antibiotic $(1 \mathrm{mg} / \mathrm{ml})$ was added to the first two wells 
of two rows, mixed, and serially diluted across the rows. Care was taken to maintain the same solvent to media ratio as used in the agar plate assay. Five to seven day old cultures of R. salmoninarum were adjusted to an O.D.520 of 0.2 or 0.1 and then diluted again with KDM-2 broth to give a final concentration of $20 \%$ cells in a total of $180 \mathrm{ul}$, an amount determined previously to reproduce the MICs of erythromycin obtained in the agar plate study. Ninety microliters of the diluted bacteria was added to every other row in the microtiter plate. In the other rows, $90 \mathrm{ul}$ of KDM-2 was added to serve as optical comparison. Antibiotic, media, and cells totaled 180 ul in each well. The microtiter plates were covered with adherent transparent film and incubated at $160 \mathrm{C}$ on a shaker. The results were read at 7,15 , and 30 days. 


\section{RESULTS}

Agar plate assay of antibiotics: Renibacterium salmoninarum was susceptible to 51 of the experimental antibiotics at day 7 after inoculation of the agar plates (Table 2). At the higher concentrations of drug, 13 antibiotics inhibited at $35 \mathrm{mg} / \mathrm{L}$. Another 19 drugs and one control drug, oxytetracycline, were found to prevent growth at $5-10 \mathrm{mg} / \mathrm{L}$. At lower concentrations, R. salmoninarum was effectively inhibited by 19 of the antibiotics. Seven antibiotics prevented growth at the same level as penicillin G $(1 \mathrm{mg} / \mathrm{L})$, and six inhibited growth at $0.5 \mathrm{mg} / \mathrm{L}$. Five of the experimental antibiotics were inhibitory to $\mathbf{R}$. salmoninarum at the concentration of $0.1 \mathrm{mg} / \mathrm{L}$, as were erythromycin and rifampicin. One drug, 107, inhibited R. salmoninarum at $0.05 \mathrm{mg} / \mathrm{L}$.

All four strains of $\mathbf{R}$. salmoninarum, with few exceptions, reacted similarly to all drugs (Table 3 ). Initially, the type strain, ATCC 33209, was growing slowly in broth and was used at less than an O.D. 520 of 0.1. Growth for this strain was not seen until 14 to 30 days after inoculation of the plates. Thus, in 24 out of 38 drugs tested, this strain was more sensitive to the effects of the drug although the sensitivity in all but one case increased by only one dilution. In two cases, the weakly growing 33209 was actually less resistant to the effects of the drugs than the other three strains. Aside from this, antibiotic inhibition of strain 33209 was similar to the other strains. 
Table 1: List of Antibiotics

\begin{tabular}{|c|c|c|c|c|c|}
\hline Drug \# & Name or Designation & Class & Drug \# & Name or Designation & Class \\
\hline 1 & A54177 & non-macrolide & 41 & A 37812 & non-macrolide \\
\hline 2 & See 1. & non-macrolide & 42 & A39079-S I & non-macrotide \\
\hline 3 & See 1 . & non-macrolide & 43 & A70195 & non-macrolide \\
\hline 4 & See 1. & non-macrolide & 44 & A80889A\&B & non-macrolide \\
\hline 5 & See 1 & non-macrolide & 45 & A80889 Complex & non-macrolide \\
\hline 6 & A5977OA & non-macrolide & 46 & A54145A-1 & non-macrolide \\
\hline 7 & A150A & non-macrolide & 47 & A54145B & non-macrolide \\
\hline $\mathrm{a}$ & A 165 & non-macrolide & 48 & A80915A & non-macrolide \\
\hline 9 & A 32357 & non-macrolide & 49 & A80915B & non-macrolide \\
\hline 10 & A2OlA & non-macrotide & 50 & $\mathrm{~A} 80915 \mathrm{C}$ & non-macrolide \\
\hline 11 & See 1 & non-macrolide & 51 & A80915D & non-macrolide \\
\hline 12 & A3 1323F & non-macrotide & 52 & A82516 & non-macrolide \\
\hline 13 & A 272 & non-macrolide & 53 & A $82775 \mathrm{~A}$ & non-macrolide \\
\hline 14 & A83586C & non-macrolide & 54 & A82775C & non-macrolide \\
\hline 15 & A83580B & non-macrolide & 55 & A82775D & non-macrolide \\
\hline 16 & Cinoxacin & non-macrolide & 56 & A41980 & non-macrolide \\
\hline 17 & A23444 & non-macrolide & 57 & A80407B & non-macrolide \\
\hline 18 & Caerulomyci tn & non-macrolide & 58 & A47934 & non-macrolide \\
\hline 19 & Puromycin & non-macrolide & 59 & Monensin & non-macrolide \\
\hline 20 & A 38808 & non-macrolide & 60 & Pyrazofurin & non-macrolide \\
\hline 21 & A42219 & non-macrolide & 61 & A16886B & non-macrolide \\
\hline 22 & A45408 & non-macrolide & 62 & A4696.HCI & non-macrolide \\
\hline 23 & A48662 & non-macrolide & 63 & Hygromycin B & non-macrolide \\
\hline 24 & A82093 & non-macrolide & 64 & A $21978 \mathrm{Cl}$ & non-macrolide \\
\hline 25 & A 82243 & non-macrolide & 65 & A 80509 & non-macrolide \\
\hline 26 & A 82548 & non-macrolide & 66 & A38533 & non-macrolide \\
\hline 27 & A 82548 & non-macrolide & 67 & A7413 & non-macrolide \\
\hline 28 & A 83094 & non-macrolide & 68 & A2315A & non-macrolide \\
\hline 29 & A 85761 & non-macrolide & 69 & A214 & non-macrolide \\
\hline 30 & A 258228 & non-macrolide & 70- 100. & See 1 & non-macrolide \\
\hline 31 & A40104A & non-macrolide & 107 & Azitbromycin** & Macrolides \\
\hline 32 & A54556 & non-macrolide & 108 & Fosfomycin* & unknown \\
\hline 33 & A60117 & non-macrolide & 109 & Imipenen* & unknown \\
\hline 34 & A $35512 B$ & non-macrolide & 110 & Norfloxacin* & penicillim/cephalosporin \\
\hline 35 & A32256 & non-macrolide & 111 & A82846A & fluoroquinolone \\
\hline 36 & A33853 & non-macrolide & 112 & A83850A & non-macrolide \\
\hline 37 & A14187B & non-macrolide & 113 & Vancomycin $\mathrm{HCI}$ & non-macrotide \\
\hline 38 & A 14787 & non-macrolide & 114 & Apramycin & non-macrolide \\
\hline 39 & A31463A & non-macrolide & 115 & See 1 . & non-macrolide \\
\hline 40 & A31463B & non-macrolide & 116 & A56620+ & non-macrolide \\
\hline
\end{tabular}

All other antibiotics are from Lilly. 
Table 2: Effects of antibiotics on four strains of R. salmoniarum (Based on 7 day readings)

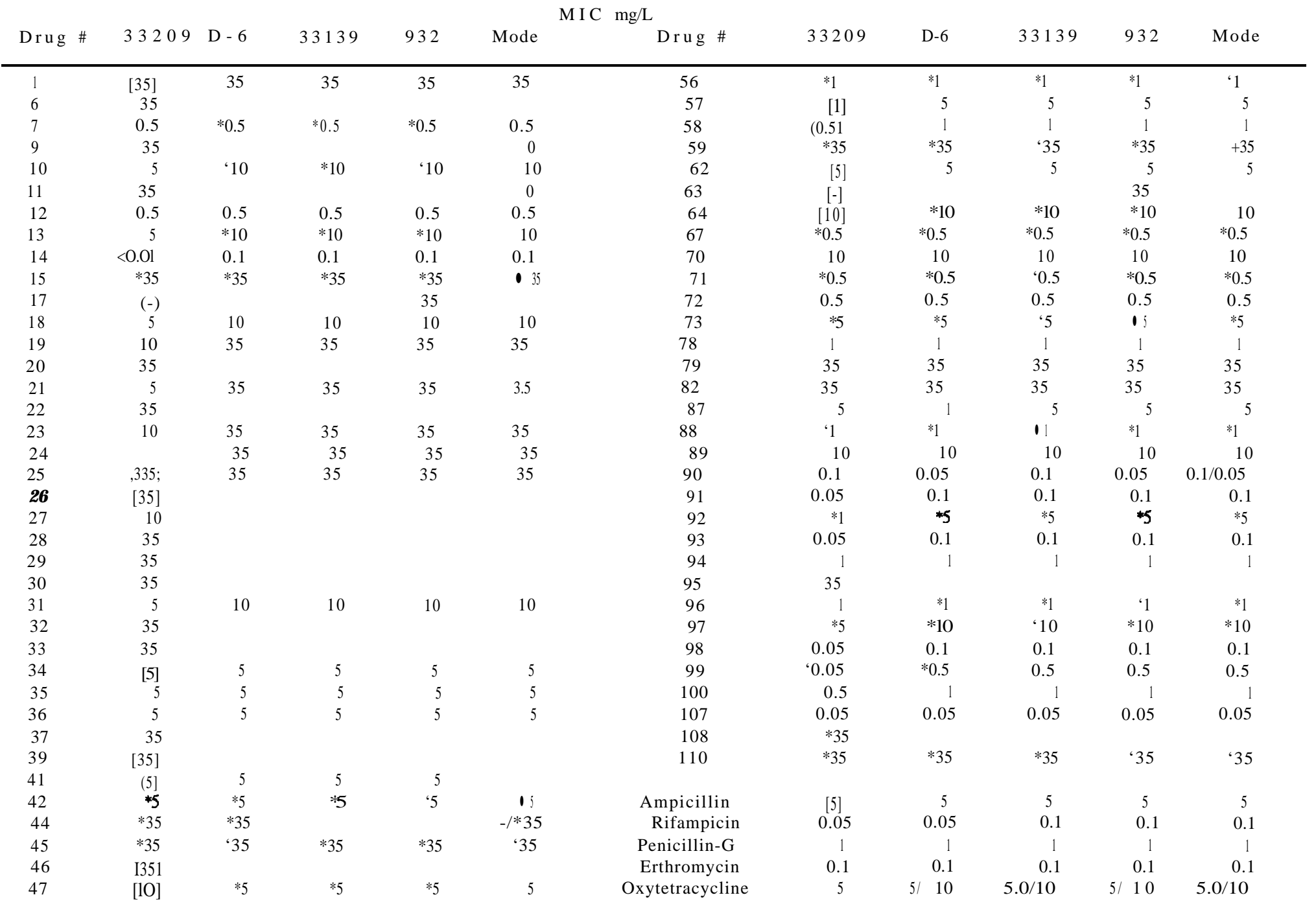

$(-)=$ no effect by drug; $*$ = change over time

[I ] = value taken from 15 or 30 day reading (no growth at 7 day). These values are not included in final evaluation of drug. 
Table 3: Effects of antimicrobial compounds on selected fish pathogens inoculated on agar plates. A (-) = no effect by drug.

\begin{tabular}{|c|c|c|c|c|c|}
\hline Drug \# & R. snlmoninarum & Slreprococcus sp. & $\begin{array}{l}\text { mg/L MIC } \\
\text { C. psychrophila }\end{array}$ & A. salmonicida & E. tarda \\
\hline 1 & 35 & & & & \\
\hline 2 & & 10 & & 10 & 10 \\
\hline 3 & & 5 & 35 & 5 & 5 \\
\hline 4 & & 5 & & 5 & 5 \\
\hline 7 & 0.5 & . & & - & . \\
\hline 9 & & & 10 & - & . \\
\hline 10 & 10 & & 10 & - & - \\
\hline 11 & & & 35 & - & - \\
\hline 12 & 0.5 & 1 & 5 & - & - \\
\hline 13 & 10 & & & & . \\
\hline 14 & 0.1 & 1 & 0.1 & . & . \\
\hline 15 & 35 & & & & \\
\hline 16 & & 10 & & & 1 \\
\hline 17 & & 35 & 35 & 35 & 35 \\
\hline 18 & 10 & & & & \\
\hline 19 & 35 & & & - & - \\
\hline 21 & 35 & 35 & 35 & . & - \\
\hline 23 & 35 & & & & \\
\hline 24 & 35 & 35 & & & \\
\hline 25 & 35 & 35 & & & \\
\hline 29 & & & 35 & & \\
\hline 31 & 10 & & 1 & 35 & \\
\hline 33 & & & 35 & 35 & 35 \\
\hline 34 & 5 & 1 & & & \\
\hline 35 & 35 & 5 & 5 & 35 & \\
\hline 36 & 5 & 35 & 35 & & \\
\hline 37 & & & & & \\
\hline 39 & & 10 & 35 & - & - \\
\hline 40 & & 35 & 10 & & \\
\hline 41 & 5 & 35 & 35 & 5 & 5 \\
\hline 42 & 5 & & & 10 & \\
\hline 44 & -135 & & & - & - \\
\hline 45 & 35 & & & & \\
\hline 46 & & 1 & & . & - \\
\hline 47 & 5 & 1 & & - & - \\
\hline 56 & 1 & 10 & 10 & - & - \\
\hline 57 & 5 & & & - & - \\
\hline 58 & 1 & 5 & 35 & - & - \\
\hline 59 & 35 & 10 & 10 & & \\
\hline
\end{tabular}


Table 3: (continued)

\begin{tabular}{|c|c|c|c|c|c|c|}
\hline & Drug \# & R. salmoninarum & Streptococcus sp. & $\begin{array}{l}\text { MIC } \\
\text { C. psychrophila }\end{array}$ & A. salmonicida & E. tarda \\
\hline & 61 & & & 35 & 5 & \\
\hline & 62 & 5 & 5 & & & \\
\hline & 63 & & & 35 & 35 & 35 \\
\hline & 64 & 10 & 1 & & & \\
\hline & 65 & & & 5 & & \\
\hline & 67 & 0.5 & 1 & 10 & & \\
\hline & 68 & & & 35 & & \\
\hline & 70 & 10 & 35 & 35 & & \\
\hline & 71 & 0.5 & 5 & 5 & & \\
\hline & 72 & 0.5 & 5 & 5 & & \\
\hline & 73 & 5 & 35 & 10 & & \\
\hline & 75 & & & 35 & & \\
\hline & 76 & & 35 & & & \\
\hline & 78 & 1 & 5 & 1 & & \\
\hline & 79 & 35 & & 35 & & \\
\hline & 81 & & & 35 & & \\
\hline & 82 & 35 & & 10 & & \\
\hline & 84 & & & 10 & & \\
\hline$\overline{0}$ & 87 & 5 & 5 & & & \\
\hline$\infty$ & 88 & 1 & 1 & 35 & & \\
\hline & 89 & 10 & 35 & & & \\
\hline & 90 & 0.1 & 1 & & & \\
\hline & 91 & 0.1 & 0.5 & 10 & & \\
\hline & 92 & 5 & & 5 & & \\
\hline & 93 & 0.1 & 1 & 35 & 35 & 35 \\
\hline & 94 & 1 & 5 & 5 & & \\
\hline & 95 & & & 35 & & \\
\hline & 96 & 1 & 10 & 35 & 35 & \\
\hline & 97 & 10 & & 35 & & 35 \\
\hline & 98 & 0.1 & 1 & 35 & 10 & \\
\hline & 99 & 0.5 & 5 & 35 & 35 & \\
\hline & 100 & 1 & 5 & 35 & 35 & \\
\hline & 107 & 0.05 & 0.5 & 35 & 5 & 10 \\
\hline & 110 & 35 & & 35 & 0.5 & \\
\hline & Ampicillin & 5 & 1 & 1.15 & 5 & 35 \\
\hline & Rifampicin & $0.1 / 0.05$ & & 1 & 5 & 35 \\
\hline & Penicillin G & 1 & $1 . / 0.5$ & 5 & 10 & \\
\hline & Erythromycin & 0.1 & 0.5 & 5 & 10 & \\
\hline & Oxytetracycline & $10 / 5$ & 5 & 35 & 5 & \\
\hline
\end{tabular}


The sensitivity of $\mathbf{R}$. salmoninarum to twenty antibiotics and one control drug, rifampicin, decreased over 30 days (Table 4). A fivefold decrease in sensitivity occurred with four experimental drugs $(7,42,47$ and 73). The change was even more extreme for rifampicin, whose MIC increased from 0.5 to $35 \mathrm{mg} / \mathrm{L}$ at 14 days. Five other drugs $(15,24,25,45,59$, and 110), that initially inhibited growth of $\mathbf{R}$. salmoninarum at $35 \mathrm{mg} / \mathrm{L}$, did not prevent growth after several more weeks of incubation. The other ten antibiotics permitted further growth of the R. salmoninarum, but still had measurable MICs.

The gram positive bacterium, Streptococcus sp., was inhibited by 33 of the 51 drugs which inhibited R. salmoninarum (Table 2). Streptococcus was also inhibited by nine other antibiotics, with significant inhibition by drugs 3, 4, and 46, that did not affect $\mathrm{R}$. saimoninarum. Twenty-two of the drugs, inhibited R. salmoninarum to a greater extent than Streptococcus; thirteen (14, $36,41,56,71,72,73,90,93,96,98,99,107)$ were significantly more inhibitive (greater than or equal to two dilution decrease in MIC). Only five antibiotics $(34,35,47,59,64)$ inhibited Streptococcus more than R. salmoninarum. All five of the control drugs prevented growth of both $\mathbf{R}$. salmoninarum and Streptococcus, but rifampicin and ampicillin produced significantly more or less inhibition, respectively, in R. salmoninarum. The three gram negative bacteria, A. salmonicida, C. psychrophila, and E. tarda, showed differential sensitivity to the antibiotics (Table 2). Of the three, C. psychrophila was inhibited by 
Table 4: Changes in MIC over time.

\begin{tabular}{|c|c|c|c|}
\hline \multicolumn{4}{|c|}{ MIC mg/L } \\
\hline Antibiotic \# & Day 7 & Day 14 & Day 30 \\
\hline 7 & 0.5 & 1 & 5 \\
\hline 13 & 10 & 35 & 35 \\
\hline 15 & 35 & 35 & - \\
\hline 24 & 35 & & - \\
\hline 25 & 35 & 35 & - \\
\hline 35 & 5 & 5 & 10 \\
\hline 42 & 5 & 5 & 35 \\
\hline 45 & 35 & 35 & - \\
\hline 47 & 5 & 10 & 35 \\
\hline 56 & 5 & 5 & 10 \\
\hline 59 & 35 & 35 & \\
\hline 64 & 10 & 35 & 35 \\
\hline 67 & 0.5 & 1 & 1 \\
\hline 71 & 0.5 & 1 & 1 \\
\hline 72 & 0.5 & 0.5 & 1 \\
\hline 73 & 5 & 10 & 35 \\
\hline 92 & 5 & 10 & 10 \\
\hline 96 & 1 & 5 & 5 \\
\hline 97 & 10 & 35 & 35 \\
\hline 110 & 35 & & \\
\hline rifampicin & $0.1 / .05$ & $0.5 / 35$ & 35 \\
\hline
\end{tabular}


more antibiotics (47) than the other two. Twenty-seven antibiotics and oxytetracycline prevented growth at $35 \mathrm{mg} / \mathrm{L}$; whereas, another 18 drugs and erythromycin inhibited growth at 5-10 mg/L. Those drugs most effectively inhibiting C. psychrophila were 31,78 , erythromycin, and rifampicin (1 .O mg/L) and 14 (0.1 mg/L).

In contrast, A. salmonicida was sensitive to only 15 of the experimental antibiotics. Nine drugs produced MICs of $35 \mathrm{mg} / \mathrm{L}$; whereas, three others and the control drugs penicillin $G$ and erythromycin inhibited growth at $10 \mathrm{mg} / \mathrm{L}$. Ampicillin, rifampicin, oxytetracycline and five experimental antibiotics prohibited growth at $5 \mathrm{mg} / \mathrm{L}$. One drug (110) killed A. salmonicida at the concentration of $0.5 \mathrm{mg} / \mathrm{L}$.

Of the three gram negative bacteria, E. tarda proved the most resistant, being inhibited by only 11 experimental and two of the control antibiotics. Rifampicin, penicillin G, and five other drugs, prevented bacterial growth at the highest concentration, $35 \mathrm{mg} / \mathrm{L}$. Better inhibition was obtained by two antibiotics at $10 \mathrm{mg} / \mathrm{L}$ and three at $5 \mathrm{mg} / \mathrm{L}$; however, the best inhibition $(1 \mathrm{mg} / \mathrm{L})$ was induced by 16 , a drug which was effective against only one other bacterium,

\section{Streptococcus.}

Although the antibiotics provided were intended for testing only gram positive bacteria, many also inhibited the gram negative organisms. Three drugs $(44,93,107)$ plus ampicillin, inhibited all bac teria tested. Five other experimental drugs $(35,96,98,99,100)$ and penicillin $\mathrm{G}$, erythromycin and oxytetracycline also had a broad inhibitory reaction against all bacteria except E. tarda. In addition, 
another two drugs, 3 and 17, were effective against all bacteria but R. salmoninarum. Two antibiotics $(33,63)$ inhibited just the gram negative and eight drugs $(21,24,25,34,47,62,87,89)$ inhibited the gram positive only. Seventeen of the drugs inhibited only the two gram positive bacteria and the gram negative C. psychrophila. A total of 32 of the experimental compounds $(5,6,8,20,22,26-28$, $30,32,37,38,43,48-55,60,66,69,74,77,80,83,85,86,108$, 109) had no inhibitory effect on any of the bacteria.

Microtiter plate assay of antibiotics: Five control and 18 experimental antibiotics were tested in 96-well microtiter plates and the MIC of each for R. salmoninurum were compared to the results from the agar plate method (Table 5). Of the 23 antibiotics, the MIC of 18 drugs were essentially the same for both methods. Eight drugs $(5,25,34,42,84,99$, penicillin and erythromycin) had the same MIC in both procedures. For six drugs (18, 64, 92, 96, 98, and 107), the microtiter plate assay was less sensitive; however, this was only a difference of one dilution. Eight antibiotics (12, 14, 17, 58, 62, 67, ampicillin, and rifampicin) inhibited $\mathbf{R}$.

salmoninarum more in the microtiter plate assay, four of these without a significant difference $(17,58,62$, and ampicillin). The other four, (12, 14, 67, and rifampicin), significantly inhibited the growth of $\mathrm{R}$. salmoninarum in comparison to the agar plate assay. One control drug, oxytetracycline, when dissolved in water, failed to inhibit growth in the microtiter assay; however, when it was dissolved in DMSO:methanol, its effective MIC was $0.5 \mathrm{mg} / \mathrm{L}$. 
Table 5: Comparison of microtiter plate and agar plate assay

\begin{tabular}{lcc} 
Drug \# & Microtiter & MIC (mg/L) \\
& & Agar plate \\
\hline 5 & $*<0.01$ & $* 0.5$ \\
12 & $*<0.01$ & $* 0.1$ \\
14 & 31.5 & \\
17 & 31.5 & 10 \\
18 & 31.5 & 35 \\
25 & 5 & 5 \\
34 & 5 & 5 \\
42 & 0.5 & 1 \\
58 & 0.5 & 5 \\
62 & & 10 \\
64 & $*<0.01$ & $* 0.5$ \\
67 & & \\
84 & 10 & $* 1$ \\
92 & $* 5$ & 0.1 \\
96 & 0.5 & 0.5 \\
98 & 0.5 & 0.05 \\
99 & 0.1 & 5 \\
107 & 1 & $0.1 / 0.05$ \\
Ampicillin & $<0.01$ & 1 \\
Rif ampicin & $0.5 / 1$ & 0.1 \\
Penicillin & 0.1 & $10 / * 5$ \\
Erythromycin & $-/ * 0.5$ & \\
Oxytetracycline & & \\
(-) no effect by drug & & \\
$*$ compound dissolved in & DMSO:methanol & \\
& &
\end{tabular}


Six antibiotics $(111,112,113,114,115$, and 116) were tested by the microtiter plate assay alone (Table 6). Drug 115 was very effective $(0.5 \mathrm{mg} / \mathrm{L})$ in inhibiting growth of $\mathbf{R}$. salmoninarum; whereas, three others $(111,112$, and 113) prevented growth at 5 mg/L. The antibiotics, 114 and 116 were the least inhibitory at 25 $\mathrm{mg} / \mathrm{L}$. There were inconsistencies in the readings for the different strains of R. salmoninarum; however, what contributed to this is unknown because this did not occur in the agar plate assay or in the two previous microtiter plate assays using the two strains 932 and ATCC 33739. 
Table 6: Microtiter plate test of six experimental antibiotics not tested by agar plate method.

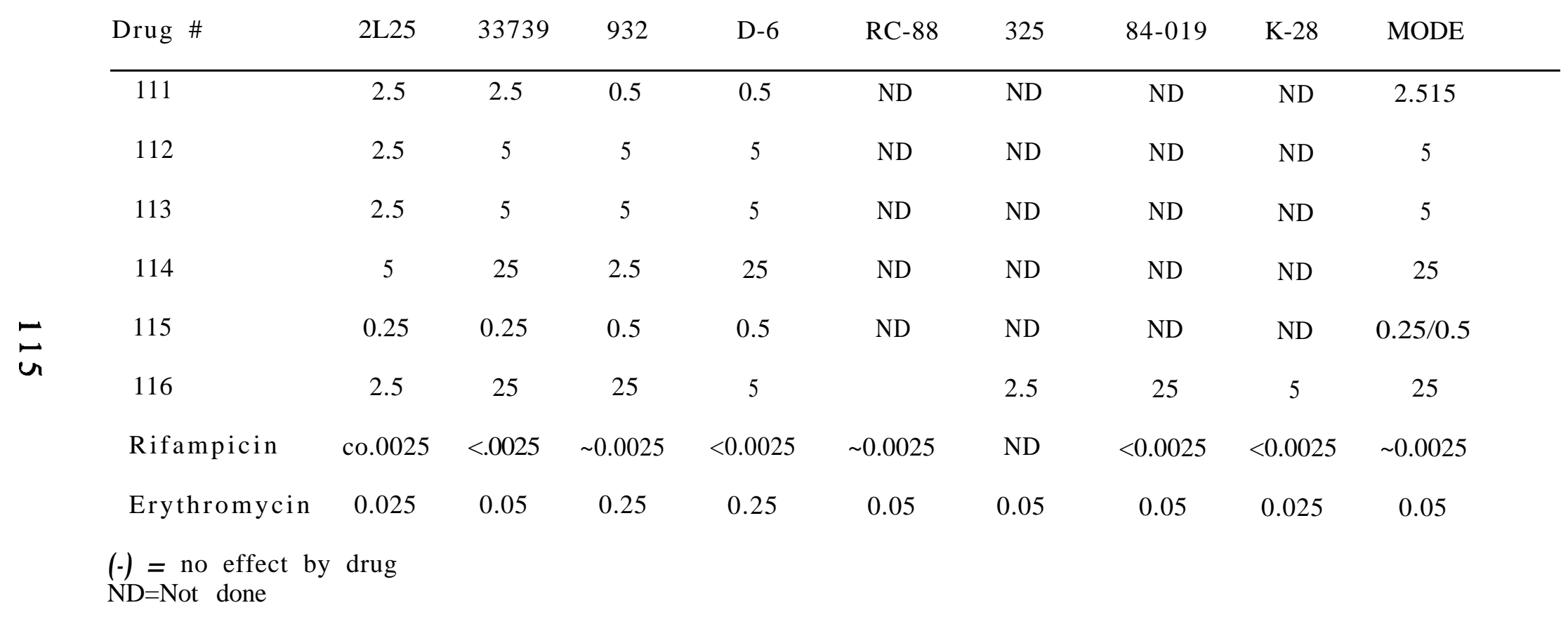




\section{DISCUSSION}

In a study by Austin (1985) over 70 commercially available antimicrobial compounds were incorporated into KDM-2 agar and tested on isolates of R. salmoninarum. Five of the antibiotics tested (ampicillin, rifampicin, penicillin $\mathrm{G}$, erthromycin phosphate, and oxytetracycline) were incorporated as controls into our study of over 100 new, untested drugs. A majority of these are unnamed, designated by the company with a number only; however, some are on the market for chemotherapeutic use. All but six of the new, experimental drugs were incorporated into KDM-2 agar and their minimum inhibitory concentration (MIC) evaluated. In addition, twenty-three antibiotics, including 18 experimental and five control drugs, were tested in the newly developed microtiter plate assay and compared to the agar plate method for determination of MIC. Because the microtiter plate results were equivalent to the agar plate results, the last six antibiotics were tested by the microtiter plate assay only.

Although the results were essentially the same, there were differences in the two assays, based on the media. In the microtiter method, in which the $\mathbf{R}$, salmoninarum were suspended in KDM-2 broth, the early seven day reading was $25 \%$ more likely to produce a false negative result than the readings at 15 and 30 days. On the solid KDM-2 agar, the colonies of $\mathbf{R}$. salmoninarum were distinct and easily read at this time. Another difference between the two methods was that the development of resistance by $\mathbf{R}$. 
salmoninarum to some antibiotics. was apparent on the agar media at the end of 30 days, unlike the microtiter plates where there was no change from the initial MIC. This was particularly obvious in the agar plate assay with the control drug, rifampicin, whose MIC changed 350 fold $(0.1 / 0.05$ to $35 \mathrm{mg} / \mathrm{L})$ over the 30 day period. Rifampicin inhibits bacterial growth by binding the RNA polymerase enzyme and blocking nucleic acid synthesis, but many bacteria, including $\mathbf{R}$. salmoninarum, can develop a resistant RNA polymerase within two cell divisions (Williams and Kruk, 1981). In the microtiter plate assay, however, rifampicin appeared to either kill or inhibit R. salmoninarum so effectively that resistant growth was not seen by 30 days.

In addition, R. salmoninarum was markedly more sensitive to some drugs $(12,14,67$, oxytetracycline, and rifampicin) in the microtiter plate assay. Four of these drugs, excluding rifampicin, were solubilised in a small amount (1:25) of DMSO, which in solution may have permitted better penetration of the drug into the bacterial cells. These same antibiotics were also very effective inhibitors in the agar plate assay, however, not to the extent seen in the microtiter plates. Alone, DMSO at any concentration used did not inhibit growth of $\mathbf{R}$. salmoninarum in either the microtiter or agar plate assays. The effectiveness of DMSO as a solvent was demonstrated by oxytetracycline. When this drug was diluted in water, it inhibited R. salmoninarum at $10 \mathrm{mg} / \mathrm{L}$ in the agar plate assay and failed to inhibit the bacterium in the microtiter plate assay. The efficacy of oxytetracycline, when solubilized with DMSO, 
increased to $5 \mathrm{mg} / \mathrm{L}$ in the agar plate assay and to $0.5 \mathrm{mg} / \mathrm{L}$ in microtiter plate assay.

We were successful in finding twenty drugs which would effectively inhibit R.salmoninarum, six of which were at least as effective as erythromycin $(0.1 \mathrm{mg} / \mathrm{L})$. Four of these were macrolides of known chemical structure (91, 92, 93, and 98; Lilly) and one was a non-macrolide (14; Lilly) with no structure given. Azithromycin was more effective than rifampicin, inhibiting $\mathbf{R}$. salmoninarum bactericidally at concentrations of $0.05 \mathrm{mg} / \mathrm{L}$.

Another 14 prevented the growth of $\mathbf{R}$. salmoninarum at least as well or better than penicillin $(1 \mathrm{mg} / \mathrm{L})$. Those inhibiting growth at $0.5 \mathrm{mg} / \mathrm{L}$ were 7,8 , and 12 (non-macrolides; Lilly) and 71, 72, 99 and 115 (macrolides; Lilly). The other seven inhibiting at $1 \mathrm{mg} / \mathrm{L}$ were two non-macrolides (56 and 58; Lilly) and five macrolides (78, 99, 94, 96, and 100; Lilly).

Although many of the compounds tested were macrolides or macrolide derivatives which likely inhibit protein synthesis by binding the 50S ribosomal subunit (Williams and Kruk, 1981), at least two were fluoroquinolones and another was of the penicillin or cephalosporin class. The fluoroquinolones are able to penetrate intracellularly into phagocytic cells, unlike most other antibiotics, and are active against other gram positive intracellular pathogens (Neer, 1988). However, R. salmoninarum was relatively insensitive (35 $\mathrm{mg} / \mathrm{L})$ to one of the fluoroquinolones, 110 (norfloxacin), and differentially sensitive to the other, 116, with the MIC ranging from 
$0.25 \mathrm{mg} / \mathrm{L}$ to no effect. The penicillin-type antibiotic, imipenim (109) had no effect on R. salmoninarum.

This study has demonstrated that a number of antibiotics inhibit R. salmoninarum in vitro, some more effectively than those currently in use. The true efficacy and/or toxicity of these antimicrobial agents in vivo remains to be determined. 


\section{ACKNOWLEDGEMENTS}

The authors thank the pharmaceutical companies which willingly supplied antimicrobial compounds for use in this study which was supported by Bonneville Power Administration under contract No. AE-A179-83 BP 11987; Alan Ruger, contracting officer's technical representative. 


\section{REFERENCES}

Austin, B. 1985. Evaluation of antimicrobial compounds for the control of bacterial kidney disease in rainbow trout, Salmo gairdneri Richardson. Journal of Fish Diseases. 8:209-220.

Bell, G.R., G.S. Traxler, and C. Dworschak. 1988. Development in vitro and pathogenicity of an erythromycin-resistant strain of Renibacterium salmoninarum, the causative agent of bacterial kidney disease in salmonids. Diseases of Aquatic Organisms. 4:19-25.

Fryer, J.L. and J.E. Sanders. 1981. Bacterial kidney disease of salmonid fish. Annual Review of Microbiology. 35:273-298.

Kaattari, S.L., D.D. Rockey, G. Weins, P. Turaga, and J.S. Rohovec. 1988. Bacterial kidney disease and furunculosis vaccines. Pages 451- 458 in Proceedings of the Congress of Aquaculture International. September 6, 1988. Vancouver, B.C., Canada.

Neer, T.M. 1988. Clinical pharmacological features of fluoroquinolone antimicrobial drugs. Journal of American Veterinary Medicine Association. 193:577-580.

Williams, R.A.D. and Z.L. Kruk. 1981. The Biochemistry and Pharmacology of Antibacterial $\underline{\mathrm{C} \mathrm{r} \text { o o }} \mathrm{m} \mathrm{H} \mathrm{e} 1 \mathrm{~m} \mathrm{~L} \mathrm{t} \mathrm{d}$, London. Pages 61-63 and 74 .

Wolf, K. and C.E. Dunbar. 1959. Tests of 34 therapeutic agents for control of kidney disease in trout. Transactions of the American Fisheries Society. 88:117-124. 


\section{SUMMARY OF EXPENDITURES}

Salary

Fringe

Utilities

Supplies

Travel

Indirect Costs

Sub-Contract

$\begin{array}{rr} & 41,130.73 \\ 10,640.16 \\ 3,429.47 \\ 14,923.14 \\ 2,743.91 \\ 25,303.90 \\ \\ \\ \\ \\ \end{array}$

